\title{
WestVirginiaUniversity
}

THE RESEARCH REPOSITORY @ WVU

Graduate Theses, Dissertations, and Problem Reports

2017

\section{The Effect of Implant Prostheses Complications on Patient Satisfaction}

Jessica Elyse Canallatos

Follow this and additional works at: https://researchrepository.wvu.edu/etd

\section{Recommended Citation}

Canallatos, Jessica Elyse, "The Effect of Implant Prostheses Complications on Patient Satisfaction" (2017). Graduate Theses, Dissertations, and Problem Reports. 5307.

https://researchrepository.wvu.edu/etd/5307

This Thesis is protected by copyright and/or related rights. It has been brought to you by the The Research Repository @ WVU with permission from the rights-holder(s). You are free to use this Thesis in any way that is permitted by the copyright and related rights legislation that applies to your use. For other uses you must obtain permission from the rights-holder(s) directly, unless additional rights are indicated by a Creative Commons license in the record and/ or on the work itself. This Thesis has been accepted for inclusion in WVU Graduate Theses, Dissertations, and Problem Reports collection by an authorized administrator of The Research Repository @ WVU. For more information, please contact researchrepository@mail.wvu.edu. 
The Effect of Implant Prostheses Complications on Patient Satisfaction

Jessica Elyse Canallatos, D.D.S.

Thesis submitted to the

\author{
School of Dentistry \\ At West Virginia University \\ in partial fulfillment of the requirements \\ for the degree of \\ Master of Science \\ In \\ Prosthodontics
}

\author{
Matthew S. Bryington, D.M.D., M.S. (Chair) \\ Bryan D. Dye, D.D.S., M.S., F.A.C.P. \\ Elizabeth Kao, D.M.D.
}

Department of Restorative Dentistry

Morgantown, West Virginia

2017

Keywords: Implant Prostheses Complications, Patient Satisfaction, Oral Health-Related Quality of Life Survey, Quality of Life

Copyright 2017 Jessica Canallatos 


\section{ABSTRACT \\ The Effect of Implant Prostheses Complications on Patient Satisfaction Jessica Elyse Canallatos, D.D.S}

Objectives: To evaluate patient satisfaction with regards to implant prostheses and compare those who have experienced self-reported implant prostheses complications to those who have not. Through this observation, we intend to determine how and if implant-related complications affect the patients' self-reported quality of life.

Methods: In this retrospective study, data were gathered from 176 edentulous and partially dentate patients who have received implant prostheses including implant-supported crowns, implant supported overdentures, and hybrid prostheses from January 1, 2010 to December 31, 2014 at West Virginia University School of Dentistry (Morgantown, WV). Demographics and complications with implant prostheses were self-reported via a survey, and patients rated their oral health-related quality of life using the QoLIP-10 questionnaire.

Results: Statistically significant differences of patient satisfaction were found among combined prostheses' complications, gender, and marital status. The most common complication for implant-supported crowns was crown loosening, and the most common complication for implant supported overdentures and hybrid prostheses wearers was repair of the prosthesis. The patient satisfaction by type of prosthesis, education, and age did not demonstrate a significant difference. Those who had experienced complications with implant prostheses reported lower quality of life compared to those who have not experienced complications. Females and widowers overall reported lower quality of life in both categories. Females' quality of life scores for with and without complications were not statistically different. The lowest satisfaction in patients without complications for implant-supported crown wearers was in the questionnaire category of "performance," including oral hygiene difficulties. The lowest satisfaction in patients with complications for implant supported overdentures and hybrid prostheses wearers was in the questionnaire category of "biopsychosocial," which includes worry/concern due to problems with the implant prosthesis.

Conclusions: The results of this survey suggest patients who have experienced complications with their implant prostheses reported a lower quality of life than those who have not. More specifically, females and widowed persons reported the lowest quality of life. Satisfaction in the survey questions regarding oral hygiene difficulty and worry/concern regarding problems with implant prostheses were lowest for implant-retained crown wearers without complications and removable/hybrid prostheses wearers with complications, respectively. Future studies are needed to evaluate patient satisfaction comparing complications with and without implants, in order to determine if patients who have had complications with implant prostheses are more satisfied than those who have experienced complications with conventional prostheses. 


\section{DEDICATION}

I would like to dedicate this paper to my mother, Dora M. Silvestri, who exhibited compassion and sympathy toward others. I owe much of my accomplishments to her because of her love, support, guidance, and value for education. Thank you for always encouraging me to strive for my goals. 


\section{ACKNOWLEGEMENTS}

I would like to thank the following individuals for providing much needed guidance during my postdoctoral training:

Dr. Matthew S. Bryington, Thank you for teaching me throughout the last three years. You have taught me what it means to provide comprehensive care for our patients, and I appreciate the knowledge you have shared.

Dr. Bryan D. Dye, Thank you for your efficiency and support throughout this process. You have helped make a seemingly impossible task less stressful because of your mentorship. I appreciate your guidance along the way.

Dr. Elizabeth Kao, Thank you for your help in my times of need and for your guidance.

Dr. Rick Jurevic, Thank you for your support and guidance through this process, especially with organizing and filling out paperwork.

Dr. Christina DeBiase, Thank you for reviewing my paper and offering guidance through the writing process.

Dr. Gerald Hobbs, Thank you for your statistical expertise. 


\section{TABLE OF CONTENTS}

ABSTRACT

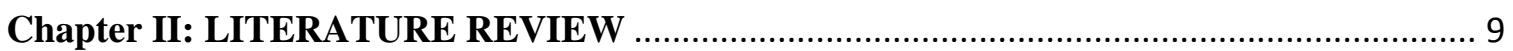

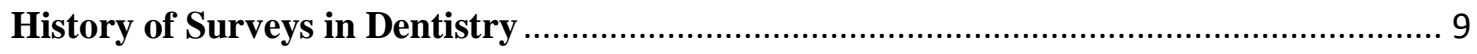

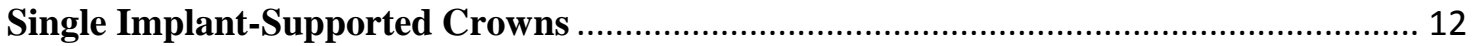

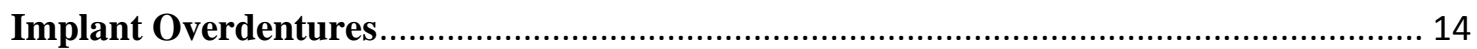

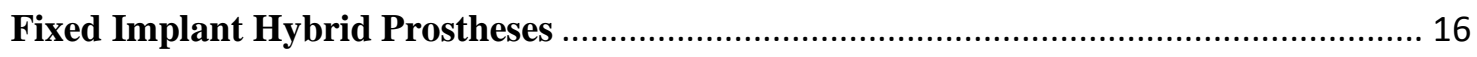

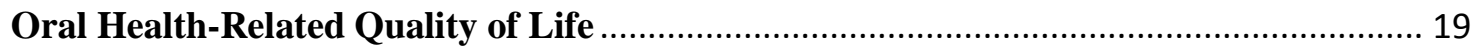

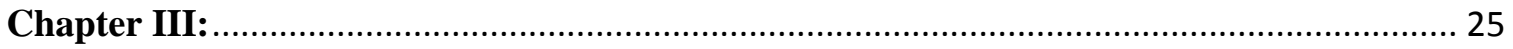

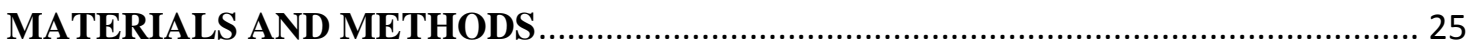

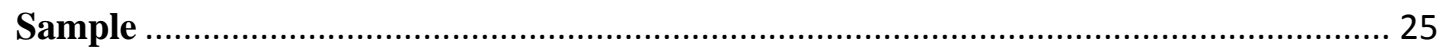

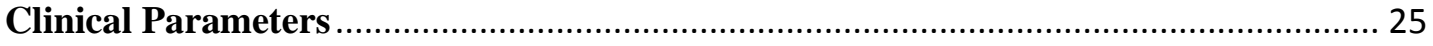




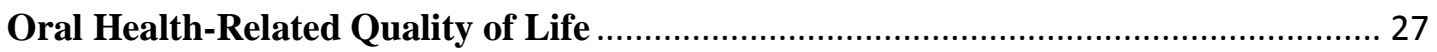

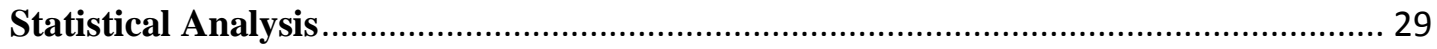

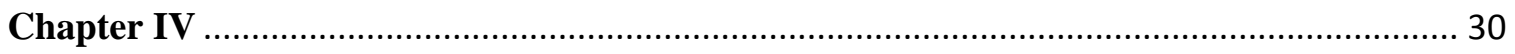

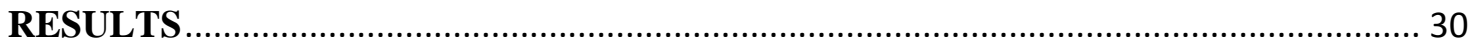

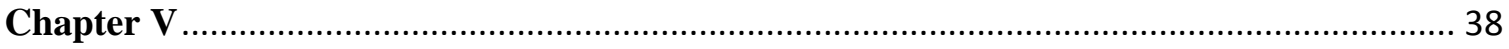

DISCUSSION

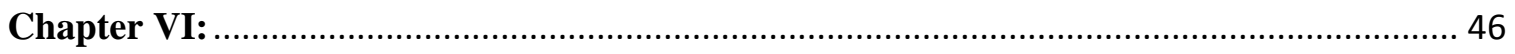

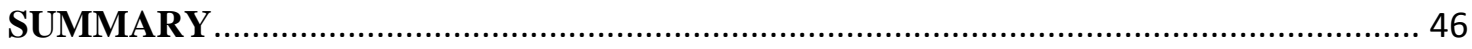

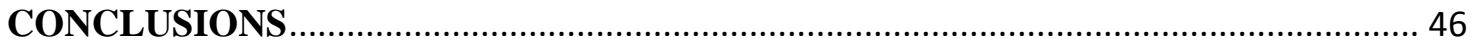

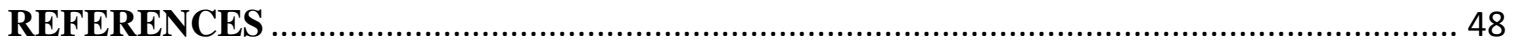

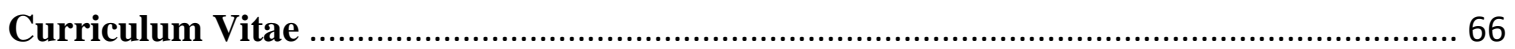




\section{LIST OF TABLES}

Table 1a. Frequencies of complications with implant-supported crowns.

Table 1b. Frequencies of complications with implant overdentures or hybrid prostheses.

Table 2. One-way ANOVA of averaged scores between type of prosthesis.

Table 3. Factor analysis of the QoLIP-10 index for implant prostheses wearers.

Table 4. One-way ANOVA among averaged question scores.

Table 5. Tukey-Kramer HSD defining significance among questions for implantsupported crowns with no complications.

Table 6. Tukey-Kramer HSD defining significance among questions for implant overdenture and hybrid prostheses wearers with complications.

Table 7. One-way ANOVA evaluating means of scores and statistical significance by sociodemographic factors.

Table 8. Tukey-Kramer HSD defining significance among averaged scores based on marital status.

Table 9. One-way ANOVA evaluating females with and without complications. 


\section{LIST OF FIGURES}

Figure 1a. Illustrations and self-reported complications questions for implant overdenture and fixed detachable wearers.

Figure 1b. Illustrations and self-reported complications questions for implant crown prosthesis wearers.

Figure 2. Demographic questions from survey.

F igure 3. QoLIP-10 questionnaire.

Figure 4. One way Analysis of Averaged Score by the Presence or Absence of Complications (JMP/Pro Ver12, SAS Inst. Inc., Cary, NC).

Figure 5. One-way Analysis of Averaged Score by the type of Prosthesis (JMP/Pro Ver12, SAS Inst. Inc., Cary, NC).

Figure 6. Averaged satisfaction scores by question (JMP/Pro Ver12, SAS Inst. Inc., Cary, NC). 


\section{LIST OF ABBREVIATIONS}

A-P- anterior-posterior

CAD/CAM- Computer aided design, computer assisted manufacturing

cRBB- Cantilevered resin-bonded bridges

FDP- Fixed Dental Prosthesis

GOHAI- Geriatric/General Oral Health Assessment Index

ISC- Implant-supported crown

OHIP- Oral Health Impact Profile

OHIP-49- Oral Health Impact Profile: 49-question survey

OHRQoL- Oral Health-Related Quality of Life

QoL- Quality of Life

QoLIP-10- Quality of Life with Implant Prostheses: 10-question survey

RPD- Removable Partial Denture

VAS- Visual Analogue Scale 


\section{CHAPTER I: INTRODUCTION}

\section{Background}

Implants have proven to provide an increase in the oral health-related quality of life for prosthodontic patients. The placement of two implants in the mandible for an implant-retained mandibular overdenture is now considered standard of care for edentulous patients ${ }^{1}$. Historically, fixed dental prostheses (FDP) and removable partial dentures (RPD) were the treatments of choice as non-invasive treatment options for replacement of single teeth. The dental procedure of replacing missing teeth by means of the fixed dental prosthesis is a common practice ${ }^{2}$. Due to the high predictability and longterm success rate in the literature regarding implants ${ }^{3}$, implant-retained and implantsupported prostheses are increasing in popularity to replace missing teeth, whether it is a single tooth or an entire arch of teeth.

The possibilities for treatment options in the implant patient are increasing, and ever-growing patient knowledge regarding implants, due to the internet, television, and modern day sources have caused a rise in implant prostheses. As a result of growth of patient knowledge, there is an increased demand for high quality prosthetic outcomes ${ }^{4}$. Patients' perception of the prosthetic outcome can affect the patients' satisfaction with their dental treatment, oral health-related quality of life, and ultimately, the patients' general health.

Despite the advancements in dental diagnosis, treatment, and materials, restoration failure still occurs. Failures due to abutment loosening, screw loosening, crown fracture, or loss of retention are some of the many reasons that may necessitate adjustment, removal, or replacement of an implant prosthesis. In situations where complications do occur, the patients' satisfaction and quality of life could also be affected.

\section{Statement of the Problem}

Do complications regarding implant prostheses affect the patients' satisfaction 
and oral health-related quality of life?

\section{Significance of the Problem}

A marked increase in the patients' desire for implant-retained and implantsupported prostheses has occurred over the last decade. Similarly, with tooth loss being a common problem, the use of dental implants is also a common practice ${ }^{5}$. Due to the higher demand of implant prostheses, the dental literature has many reports on the ways in which implant prostheses have been proven to significantly enhance the patients' oral health-related quality of life. Furthermore, patients' perceptions of health needs and treatment outcomes are important to consider in both medical and dental practices. The loss of teeth can create a hindrance to the patients' quality of life, and the impact of replacing these missing teeth on quality of life should be considered when diagnosing and treatment planning.

A limited number of articles are available to describe the impact of complications with implant prostheses on oral health-related quality of life. Many subjective oral health status methods known as "oral health-related quality of life" (OHRQoL) measures have been developed and validated in a wide variety of situations ${ }^{6-8}$. There have been many studies on rehabilitation complications and explicitly survival ${ }^{3}$. For example, much evidence has demonstrated the impact of mandibular implant-retained overdentures ${ }^{9}$. Likewise, in a study by Lam et al. ${ }^{10}$, the oral health-related quality of life was compared among subjects treated with implant-supported crowns and 2-unit cantilevered resin bonded bridges. They also investigated factors associated with OHRQoL among those who experience complications and found that more complications have a greater effect on OHRQoL. Complications can reduce the ability of the prosthesis to properly function and can also cause a patient to spend more time and money due to decreased longevity of the prosthesis ${ }^{10}$. Furthermore, complications can cause physical, social, and psychological issues for the subject and therefore impact the patients' quality of life. The studies mentioned have failed to evaluate whether there is a significant difference in the patients' OHRQoL when complications occur with implant prostheses versus when they do not occur. Furthermore, most studies have addressed the survival of oral rehabilitation 
prostheses and how implant prostheses have considerably improved OHRQoL compared to conventional prostheses ${ }^{11}$. While survival is important, it is essential to recognize how complications are to be considered in providing insight into the experiences and perceptions of patients ${ }^{11}$.

\section{Hypothesis}

The presence of complications with implant prostheses will have an effect on selfperceived oral health-related quality of life. The gender, marital status, age, and education of the patients will also affect quality of life and satisfaction with their prostheses.

\section{Null Hypothesis}

The presence of complications will not have an effect on self-perceived oral health-related quality of life when compared to those with no history of complications. Gender, marital status, age, and education of the patients will not have an effect on their quality of life or satisfaction with their prostheses. 


\section{Definition of Terms}

All-ceramic restoration: a ceramic fixed dental prosthesis that restores a clinical crown without a supporting metal framework ${ }^{12}$.

Abutment screw- that component which secures the dental implant abutment to the dental implant body ${ }^{12}$.

Attachment- 1: a mechanical device for the fixation, retention, and stabilization of a prosthesis 2: a retainer consisting of a metal receptacle and a closely fitting part; the former (the female \{matrix \} component) is usually contained within the normal or expanded contours of the crown of the abutment tooth and the latter (the male \{patrix\} component), is attached to a pontic or the denture framework ${ }^{12}$.

Attachment screw- any component used to secure a fixed dental prosthesis to the dental implant abutment(s) ${ }^{12}$.

Crown- an artificial replacement that restores missing tooth structure by surrounding part or all of the remaining structure with a material such as cast metal, porcelain, or a combination of materials such as metal and porcelain ${ }^{12}$.

Dental implant- a prosthetic device made of alloplastic material(s) implanted into the oral tissues beneath the mucosal or/and periosteal layer, and on/or within the bone to provide retention and support for a fixed or removable dental prosthesis; a substance that is placed into or/and upon the jaw bone to support a fixed or removable dental prosthesis $^{12}$.

Dental implant abutment- the portion of a dental implant that serves to support and/or retain any fixed or removable dental prosthesis—usage: frequently dental implant abutments, especially those used with endosteal dental implants, are changed to alter abutment design or use before a definitive dental prosthesis is fabricated ${ }^{12}$.

Dental implant attachment- 1. the biochemical/mechanical interconnection between the dental implant and the tissues to which it is attached 2. slang expression for the means of 
retention of the dental implant abutment to the dental implant ${ }^{12}$.

Dental prosthesis- an artificial replacement (prosthesis) of one or more teeth (up to the entire dentition in either arch) and associated dental/alveolar structures. Dental prostheses usually are subcategorized as either fixed dental prostheses or removable dental prostheses $^{12}$.

Denture- an artificial substitute for missing natural teeth and adjacent tissues ${ }^{12}$.

Denture retention- 1: the resistance in the movement of a denture away from its tissue foundation especially in a vertical direction 2: a quality of a denture that holds it to the tissue foundation and/or abutment teeth ${ }^{12}$.

Fixed dental prosthesis- any dental prosthesis that is luted, screwed, or mechanically attached or otherwise securely retained to natural teeth, tooth roots, and/or dental implant abutments that furnish the primary support for the dental prosthesis ${ }^{12}$. Slang: hybrid prosthesis, fixed detachable.

Implant crown- a crown or fixed dental prosthesis is not an implantable device. The prosthesis receives support and stability from the dental implant ${ }^{12}$.

Implant dentistry- the selection, planning, development, placement, and maintenance of restoration(s) using dental implants ${ }^{12}$.

Implant prosthesis- a prosthesis is not an implantable device. Dental prosthesis such as crown and other fixed dental prostheses, removable dental prostheses as well as maxillofacial prostheses can be supported and retained in part or whole by dental implants. Terminology to assist in understanding the means of retention and support should be limited to concatenation of three and no more than four adjectives to provide clarity $^{12}$.

Metal ceramic restoration- a tooth or implant retained fixed dental prosthesis that uses a metal substructure upon which a ceramic veneer is fused ${ }^{12}$.

Nylon inserts: LOCATOR male denture caps that allow personalized retention for each 
specific patient ${ }^{13}$.

Removable complete denture prosthesis: a removable dental prosthesis that replaces the entire dentition and associated structures of the maxillae or mandible ${ }^{12}$.

Removable dental prosthesis- 1: any dental prosthesis that replaces some or all teeth in a partially dentate arch (partial removable dental prostheses) or edentate arch (complete removable dental prostheses). It can be removed from the mouth and replaced at will, 2: any dental prosthesis that can be readily inserted and removed by the patient. The means of retention for such prostheses include tissue retained $R D P$, tooth retained $R D P$, implant retained $R D P$ or tooth and implant retained $R D P^{12}$. 


\section{Assumptions}

1. It is assumed the subjects understand the questions asked in the questionnaires.

2. It is assumed the subjects answered each question honestly and truthfully.

3. It is assumed the instrument used in this study is valid and reliable.

\section{Limitations}

1. The subjects of the study were limited to patients at West Virginia University School of Dentistry. Findings may not represent larger, general population.

2. Missing data, including those who failed to participate and questions, which were left unanswered, could result in biased data and inefficient statistical estimates.

3. Questionnaire is subjective. Subjects may not have answered all questions accurately.

4. The response scale was based on ambiguous/undefined terms. One subject answering "strongly agree" may not coincide with another subject's definition of "strongly agree."

\section{Delimitations}

1. Subjects receiving implant prostheses from 2010-2014 were evaluated. Findings may be dependent on conditions during that time period.

2. In the study, there were limited self-reported complications; only those that were most common in clinics at West Virginia University School of Dentistry 
were included. 


\section{Chapter II: LITERATURE REVIEW}

\section{History of Surveys in Dentistry}

Overall general health can be defined as the combination of clinical and sociobehavioral factors. It is a composite of absolute health, comparative health, and disability rating ${ }^{14,15}$. The oral cavity provides the functions of chewing and swallowing. At another level, it also contributes to self-esteem, self-expression, communication, and facial esthetics ${ }^{14}$. Therefore, any compromise of the oral cavity can diminish selfperceived overall health. Poor oral health is correlated with staying in bed, decreased socialization, social withdrawal, lack of motivation, and less interest in nutrition ${ }^{15}$. The most common compromise of the oral cavity is loss of natural teeth. For most edentulous or partially dentate people, loss of natural teeth leads to impairment, disability, and handicap. Impairment is a result of tooth loss and loss of alveolar bone. Chewing and speaking problems can lead to disability. Handicap is a result of the effect on socialization $^{16-18}$. In an interview assessing edentulous individuals on their feelings about tooth loss, common themes included feelings of bereavement, lowered selfconfidence, altered self-image, dislike of appearance, inability to discuss this taboo subject, concern about dignity, behaving in a manner that keeps tooth loss secret, altered behavior in socializing and forming close relationships, and premature aging ${ }^{19,20}$.

Many clinicians consider prosthetic success as a result of meeting certain clinical criteria. In the past, clinical criteria were used more often than psychological criteria ${ }^{16,21}$. Moreover, health care professionals formulate treatment plans based on their own understandings and perceptions of patient quality of life, but research has proven there to be low correlation between the health care provider's perception and that of the patient $^{15,22}$. In a study of young and middle age adults in England, measures of perceived oral health were unrelated to objective measures of oral health ${ }^{15,23}$. Therefore, an understanding of the patient's definition of quality of life can help to formulate a treatment plan that is attainable by the practitioner and appropriate for the patient ${ }^{15}$. While technical considerations are important, understanding the patient's needs is also of great concern $^{24,25}$. Thus, the need for measuring the patients' perceived quality of life is 
essential for assessing outcomes of health care ${ }^{26,27}$.

As explained above, since oral health is related to general health and nutrition, it is important to consider oral health quality of life when caring for patients ${ }^{15}$. Oral quality of life is discussed in terms of self-care (hygiene), mechanical ability (speech, eating, food), perceived oral health, perceived treatment needs, reported pain, psychosocial issues, and performance limitations. People usually do not consider themselves ill until symptoms interfere with normal tasks ${ }^{28}$. Similarly, work days lost is a useful population statistic for measuring the impact of oral health status on quality of life ${ }^{15,28}$. Issues such as lack of interpersonal activities, functional impairments, declining health, and pain detract from quality of life ${ }^{15,29}$. If practitioners can understand what the individuals' expectations are of treatment, improvements in perceived and actual quality of life are possible. In the past, few studies had addressed prosthetic aspects and the perception of treatment outcomes by patients ${ }^{30-33}$.

Since patients use their prostheses well after treatment is completed, it is believed that the most appropriate judgement of care come from those who use their prostheses every day, as opposed to the practitioner who completes the treatment ${ }^{34}$. This concept has led to the idea of utilizing surveys to assess treatment success, according to the patients. Also, the use of patient reported outcome measures (PROMs) in research has increased to assess patients' opinions related to their well-being ${ }^{21,35}$. It has been proven that patient centered outcomes are more important in evaluating the overall success of prosthetic therapy ${ }^{36-40}$. Furthermore, patient expectations from treatment have been shown to be associated with actual patient reported outcome measures ${ }^{10,41,42}$. For these reasons, questionnaires have been designed in the last few decades to assess perceived outcome of treatments ${ }^{43-45}$.

Many studies have used questionnaires, which are mostly non-standardized, custom-made and designed to measure a specific prosthesis. When one examines the complete denture literature for example, several studies have demonstrated the connection between patient satisfaction and OHRQoL ${ }^{21,46-48}$. Celebic et al. ${ }^{47}$ showed that the quality of the denture-bearing area and the actual denture-wearing experience itself 
seemed to be more important in determining patient satisfaction with complete dentures. In a study by Michaud $^{34}$ et al., their results were in agreement with previous investigations that patients' satisfaction related to prosthodontic treatments is positively correlated with their OHRQoL ratings.

When forming a health status questionnaire, Stewart et al. ${ }^{49}$ believed it should represent multiple health concepts and a range of health states pertaining to general functioning and well-being, have good psychometric properties, and be simple and easy to use. In addition, specific questionnaires are preferred over generic scales to measure the impact of prosthodontic treatment on OHRQoL ${ }^{36,43}$. Several quality of life indicators may be utilized for assessing patient satisfaction, and OHRQoL is the most used measure of patient perception. An additional study has also shown that socio-demographic factors are important when considering patient related outcome measures. Therefore, these have been included in questionnaires assessing OHRQoL ${ }^{50}$. It is considered a more complete evaluation of oral disease and its treatment than general measures of satisfaction ${ }^{51}$. Now, many instruments have been created to measure oral conditions affecting quality of life. They have been successfully used in many studies, including Oral Health Impact Profile (OHIP) and its shorter versions, Geriatric/General Oral Health Assessment Index (GOHAI), Quality of Life with Implant Prostheses (QoLIP-10) and other custom-made questionnaires $^{21,48,52-55}$.

The Oral Health Impact Profile (OHIP) was one of the first questionnaires available to assess OHRQoL. It detects the impact of oral health on the quality of life of patients with total prostheses, before and after they have received treatment ${ }^{56}$. The fortynine questions in the questionnaire capture the seven dimensions of quality of life: functional limitation, physical pain, psychological discomfort, physical disability, psychological disability, social disability, and handicap ${ }^{27}$. Since forty-nine questions can be a considerable burden to answer, the popularity of shorter versions of this questionnaire has been increasing. Short questionnaires also have the added benefit of being more efficiently administered and having a higher response rate $^{27}$. Slade $^{27}$ developed a shorter version of OHIP with only fourteen questions. In the survey, for each dimension, the subjects are asked to evaluate how often they felt or experienced any 
impacts on oral health using a five-point Likert scale ${ }^{57}$.

Another survey that can be used for implant prostheses, known as QoLIP-10, measures the same constructs as OHIP ${ }^{58-60}$. However, QoLIP-10 and OHIP-14 are inversely correlated ${ }^{36}$. QoLIP-10 is a short, specific and effective questionnaire for assessing the oral health-related quality of life $(\mathrm{OHRQOL})$ of patients wearing implant prostheses and to analyze the factorial construct of the prosthetic well-being. The content validity of QoLIP-10 scale was checked in a pilot trial ${ }^{43}$. The survey is a ten item scale with three conceptual dimensions, including biopsychosocial dimension (oral pain, worry/concern, communication/social relations, activities of daily living, and chewing function), dental-facial esthetics (prosthesis' appearance, realism of the prosthesis, satisfaction with the smile), and performance dimension (speaking difficulty and oral hygiene difficulty $)^{36,43}$. The questionnaire was designed to be self-completed with responses on a Likert scale with proportional codes. The Likert responses have a symmetric format which allows for intuitive understanding ${ }^{43}$. Also, having bidirectional measurements of responses is more complete than excluding evaluation of negative effects $^{58}$. The total score is the sum of the different items. The higher the total score, the higher the satisfaction of the patient. Negative or low scores indicate poorer selfperceived quality of life ${ }^{61}$. Validity was proven by the fact that total scores were positively correlated with all of the satisfaction variables. Additionally, subjects understood the questionnaire, the instrument did not lack any important content, and content validities were confirmed. It was also confirmed that all questions needed to be included in the final questionnaire. To date, the QoLIP-10 instrument has been validated and used in cases with implant-retained overdentures, hybrid prostheses, and screwretained and cement-retained implant-supported crowns ${ }^{36,43,61}$.

\section{Single Implant-Supported Crowns}

A missing single tooth can be treated by a conventional fixed partial denture, a fixed partial denture with a cantilever, a conventional removable partial denture, or an implant-supported single tooth crown ${ }^{62}$. An implant-supported crown offers the benefit of avoiding treatment of adjacent teeth to the edentulous sites. Continuing advances in 
implant therapy have provided a tremendous advantage to patients who are partially dentate or completely edentulous. In a study by Nickenig et al. ${ }^{63}$ evaluating patients before, during, and after implant therapy, it was found that implant therapy offered the greatest benefits in edentulous arches and in single-tooth anterior sites. Single-tooth replacement is of tremendous value to the patient, allowing restoration of the dentition. The survival rate of implant-supported single crowns has been reported at rates ranging from $94.5 \%{ }^{62}$ to $96.4 \%{ }^{64}$ at 5 years.

While rehabilitation can restore functionality, it is important to remember it is not without complications. For implant-supported single crowns, those in the posterior region are more prone to complications than those in the anterior regions, according to a study by Nedir et al. ${ }^{65}$ (11\% vs. $0 \%$, respectively). Furthermore, in the same study, the complication rate is higher for cemented prostheses wearers $(10.4 \%)$ than for patients with screw-retained prostheses $(5.9 \%)$ at five years ${ }^{65}$. Complications, such as screw or abutment fracture and ceramic or veneer fractures can shorten a restoration's longevity, which requires the patient to sacrifice more time and expenses to fix the problem ${ }^{66-68}$. At an observation period of 5 years, high survival rates for implant-supported single crowns can be expected, but technical complications are frequent ${ }^{62}$. Common complications include abutment or occlusal screw loosening, loss of retention, and fracture of a veneer material $^{62}$. An annual failure rate of $1.14 \%$ has been suggested in a meta-analysis by Jung et al. ${ }^{62}$. In a study by Nedir et al. ${ }^{65}$, it was found that if complications do occur, they predominantly occur in the first year of loading. Many studies have reported no complications after three or more years of loading ${ }^{65}$.

According to Brägger et al., ${ }^{11}$ the most common prosthetic complication for implant restorations in a 10-year prospective study was screw loosening $(7.1 \%)$, followed by loss of retention $(5.4 \%)$, and lastly, porcelain fracture (.89\%). Altogether, the frequency of complications was $18.8 \%^{11}$. Screw loosening has been reported as the most frequent complication in other studies as well ${ }^{69-76}$. Factors that have been attributed to screw loosening are occlusion, prosthesis misfit, and screw design and composition ${ }^{77}$. Screw loosening is usually detected at recall appointments with mobility testing or radiographic examination ${ }^{78}$. In a cumulative study with 5-years of follow up, screw 
loosening had a cumulative rate of $12.7 \%$, loss of retention at $5.5 \%$, and porcelain fracture at $4.5 \%{ }^{62}$.

It is generally supported that complications with implant-supported crowns do not increase over time. In a study by Nedir et al. ${ }^{65}$, it was found that the cumulative percentage of complication-free fixed prostheses was $88.5 \%$ at 8 years. Therefore, the practitioner should be aware of more complications occurring earlier on in the postloading time period. Also, the presence of complications contributes and can lead to overall failure of the prosthesis.

\section{Implant Overdentures}

While the prevalence of edentulism in the United States is decreasing, continued population growth and an increased proportion of older individuals in the population create a need for treatment of edentulous patients ${ }^{79,80}$. Conventional dentures have helped to aid with the problems associated with edentulism, such as reduced oral and social function ${ }^{81}$. However, it has been found that many patients complain of the instability with the conventional denture due to the rapid rate of tissue and bone resorption that occurs, especially in the edentulous mandible ${ }^{82}$. Studies have shown an average of $4 \mathrm{~mm}$ of bone resorption occurs during the first year after tooth loss and thereafter decreases to $0.5 \mathrm{~mm}$ per year ${ }^{83}$. This means, over a five-year period, $5.2 \mathrm{~mm}$ of vertical bone height will be lost under complete dentures ${ }^{83}$. Therefore, dental implant therapy is especially important in the mandible to aid with denture stability.

Dental implants offer advantages over conventional denture therapy by improving function and comfort for the patient. It has also been found that dental implant therapy helps with edentulism by aiding in alveolar bone preservation ${ }^{79,82,84-87}$. In a 5-year follow up study by von Wowern and Gotfredsen ${ }^{88}$, the most radiopaque areas with the densest bone were found around dental implants in patients wearing mandibular overdentures. They found that not only were the bone levels around the implants maintained but in some cases, an actual increase in vertical bone height. Schwartz-Arad et al. ${ }^{89}$ found that $70 \%$ of their patients with implant-supported overdentures lost less than $.2 \mathrm{~mm}$ bone in 
the first year.

For these reasons, mandibular overdentures supported by two implants have become the standard of care for edentulous patients ${ }^{1}$. Further benefits of implant-retained overdentures include better occlusion, improved occlusal load direction, increased occlusal function, and maintenance of the occlusal vertical dimension ${ }^{83}$. While conventional dentures rely upon the residual ridge for support and retention, implantretained overdentures rely on implants for stability and retention.

Implant-retained overdentures have superior retention to conventional dentures with the help of an attachment system, such as a bar, ball, magnet, or Locator. Along with these advantages are the cumulative success rates of all implant-retained overdentures at 95.4\%, with implant-retained overdentures having a slightly higher success rate in the mandible than in the maxilla ${ }^{83}$. On average, the longevity of a mandibular overdenture prosthesis is about 12 years, with laboratory relining every 4 years ${ }^{90}$. However, like all prostheses, complications do occur and maintenance is required. While it may seem appropriate to assume a correlation between implant number and occurring complications, studies fail to support this concept. Complications are common because the denture-supporting implants are subject to biomechanical forces ${ }^{91}$. Prosthetic maintenance includes fracture components, denture relining, and replacement of the prosthesis $^{90}$. For $33 \%$ of prostheses experiencing complications, the first incident occurred during the first year of loading, while the least amount of complications occurred after the third year at $16.6 \%{ }^{65}$. In a study by Nedir et al. ${ }^{65}$, over 8 years, $66 \%$ of implant overdentures experienced complications. The most common complication was the wear of retaining components (40\%), followed by prosthesis relining (38.2\%) and reactivation of the attachment $(16.4 \%)^{65}$. It has been frequently reported in the literature that loss of retention is the most common complication with implant-supported overdentures $^{92}$.

When comparing different attachments, it has been found that bar-retained overdentures experience fewer complications than ball-retained overdentures $(42.9 \%$ versus $77.5 \%$ ). At 3 years, the incident-free prosthesis rate was $71.4 \%$ for the bar- 
retained group and $37.5 \%$ for the ball-retained group ${ }^{65}$. It is well known that attachments lose retention over time. Fatigue and wear on the nylon or silicone material could attribute to the decrease in retention. For example, a denture could rotate anteroposteriorly around a bar, or the denture may rock slightly when the patient is chewing on one side. These movements can lead to plastic deformation of the matrix, resulting in reduced retention ${ }^{91}$. All situations stated above are important considerations when determining which attachment system to use for the patient. Since every repair or replacement requires extra time and cost to the patient, a design that requires the least maintenance should be considered and preferred.

\section{Fixed Implant Hybrid Prostheses}

While implant overdentures can be removed, fixed implant hybrid prostheses, also called fixed-detachable prostheses, consist of a CAD/CAM framework covered with complete denture components screwed onto implants or abutments. Unlike dentures, the hybrid prosthesis cannot be removed every day since it is screw retained into the implants. Implant overdentures significantly improve stability, bite force, chewing efficiency and oral health, but some patients may consider their removability disadvantageous ${ }^{4}$. Hybrids provide functional and psychological advantages since they are fixed for the patients ${ }^{93}$. These implant prostheses are more similar to natural dentition in terms of functionality ${ }^{43}$. Hybrid dentures are minimally intrusive and are more stable than dentures. Also, with a fixed detachable in the maxilla, the prosthesis is horse-shoe shaped, allowing a more natural feel for the patient. They provide the advantages of both fixed and removable prostheses.

Hybrids are usually the treatment of choice when the patient presents with severe ridge atrophy, which would allow for sufficient interarch space ${ }^{94}$. Treatment planning may involve the use of four to six implants in the edentulous parasymphyseal mandible and six implants in the maxilla. Interfixture distance should allow for adequate space for hygiene and also an appropriate anterior-posterior dimension to accommodate 
mechanical stresses. Once implants are healed, they are connected to abutments which can be screwed into a reinforcing framework. If there is not an acceptable amount of interarch space for the prosthesis, modification of the prosthesis framework is necessary. Otherwise, hygiene, esthetics, speech, and strength of the prosthesis can be affected ${ }^{94}$.

In a prospective study regarding fixed detachables, by Attard and Zarb ${ }^{68}$, the overall prosthetic plan and implant outcome success rates at 20 years were $84 \%$ and $87 \%$, respectively. A systematic review of fixed implant prostheses' survival rates at 5 years and 10 years were $94.3 \%$ and $88.9 \%$, respectively ${ }^{2}$. Mean marginal bone loss around the implants after the first year was minimal at $.05 \mathrm{~mm}$ per year. Attard and Zarb ${ }^{68}$ found poor oral hygiene, smoking history, and implant position were predictors of marginal bone loss. In terms of prosthetic maintenance, it was ongoing, but the longevity of the fixed prosthesis was 8 years at the least. This confirms the long-term treatment outcome success of patients treated with fixed implant prostheses ${ }^{68}$. Nevertheless, mucositis, periimplantitis, and fracture may occur ${ }^{95}$. Some common complications involved with the metal-acrylic hybrid include fracture of the acrylic veneer, wear or debonding of the resin denture teeth, screw or abutment loosening, and fracture. Zirconia-based materials also exist for fabrication of the fixed detachable, and while these materials have attempted to solve some of the problems associated with the metal-acrylic hybrid, chipped teeth have presented as one of the common complications ${ }^{79}$. No matter what the material of choice, technical complications do occur with fixed implant prostheses.

In a prospective study by Limmer et al. ${ }^{79}$, implant fixed prostheses experienced more technical than biological problems over the course of one year. Technical complications are defined as damage to the integrity of the prostheses' meso- and suprastructures. Complications rates are estimated to be at $24.6 \%$, and the cumulative rates of complication-free prostheses at 5 and 10 years are $29.3 \%$ and $8.6 \%$, respectively ${ }^{96}$. In a systematic review, veneer fractures, abutment or screw fractures, and screw loosening were the most common complications involved with fixed implant prostheses. Veneer fractures represent the most common complication at 5 and 10 year rates of $10.3 \%$ and $19.6 \%$, respectively. The second most common complication was screw loosening at $8.2 \%$ and $15.7 \%$ for 5 and 10 years, respectively. Lastly, abutment or 
screw fractures occurred at rates of $2.1 \%$ and $4.1 \%$ for 5 and 10 years, respectively. Framework fractures and implant fractures rarely occurred in any of the current publications ${ }^{2}$. Similar results have been found in other systematic reviews with veneer fracture being the most common technical complication but occurring at higher rates of $33.3 \%$ at 5 years and $66.6 \%$ at 10 years $^{96}$.

As mentioned above, the anterior-posterior (A-P) spread, can affect abutment or prosthesis fractures. The spread varies in each patient due to arch form, mental foramen position, and accuracy of implant placement ${ }^{79}$. A ratio of 1.5 to 1 is recommended as the target value for distal extension cantilevers, and an increased ratio of cantilever length to A-P spread could cause unfavorable mechanical forces and lead to prostheses complications or failures ${ }^{79,97}$. Complications of the fixed implant hybrid prostheses do occur continuously over time as a result of fatigue and stress. While these complications may not lead to complete failure of the prostheses, they do require a significant amount of repair, maintenance, time, and cost to both the clinician and patient. Therefore, these complications need to be considered when treatment planning, and the patient must be made aware of common complications possibly occurring. 


\section{Oral Health-Related Quality of Life}

Quality of life is defined as a multidimensional construct denoting "a wide range of capabilities, limitations, symptoms, and psychosocial characteristics that describe an individual's ability to function and derive satisfaction from a variety of roles"15,98. Anything detracting from a person's capabilities or limitations can negatively affect quality of life. The term "oral health-related quality of life (OHRQoL)" was introduced by Gift and Redford in 1992 to focus on the functional, social, and psychological impacts of oral disease ${ }^{34,52}$. Poor oral health can affect quality of life in many different aspects, such as chewing, swallowing, self-esteem, self-expression, communication, and esthetics. Furthermore, individuals experiencing oral symptoms are less likely to enjoy a high quality of life. An example is eating. Eating is not only social, but it is emotionally and physiologically necessary for the person ${ }^{15,99}$. It has been found that chewing ability is correlated with mandibular dysfunction and parafunction. Similarly, reduced ability is associated with lower levels of general health ${ }^{100,101}$. Also, poor esthetics of the orofacial area causes more negative responses than poor esthetics of any other part of the body ${ }^{15}$. If a person is unhappy with the esthetics of the face, social and interpersonal relationships can suffer ${ }^{15,102}$.

Studies have indicated that oral health-related quality of life is reduced by total tooth loss and other pathological conditions reflecting discomfort ${ }^{16}$. Similarly, loss of teeth leads to impairment, disability, and handicap ${ }^{20}$. Prosthodontists attempt to alleviate these reduced abilities through fabrication of prostheses to replace missing teeth. Stober et al. ${ }^{103}$ found a significant association between general satisfaction and OHRQoL for patients receiving conventional complete dentures. Yet, problems can still exist. For example, dentures that are unsatisfactory limit the patients' ability to eat satisfactorily, speak clearly, and laugh freely ${ }^{15,104}$. While dentures can significantly improve a patient's quality of life, they can also hinder it if there is lack of retention, stability, or support. However, there are a group of patients who still remain dissatisfied with their dentures even with reported clinical perfection of the prostheses ${ }^{105-108}$. 
In a study evaluating the level of association between edentulous patients' ratings of denture satisfaction and OHRQoL, it was found that no matter the socio-demographic factors, an improvement in oral condition and chewing ability will be associated with improvement in OHRQoL. In the same study, chewing ability and oral condition were found to be the best determinants of $\mathrm{OHRQOL}^{34}$. Similar results of using chewing ability as the main determinant of denture satisfaction best associated with oral health-related quality of life have been found in other studies ${ }^{20,34,36,43}$. Lastly, patient assessed measures of chewing are more positive than objective measures ${ }^{109}$. Therefore, lack of clinical perfection may not always translate to the patient in the same manner. Success could be a factor of patient subjectivity rather than clinical objectivity.

The effectiveness of implant prostheses depends on recovering oral function, esthetics, and social life. This is influenced by tissues, prostheses design, connection system, and the patient's subjectivity ${ }^{110,111}$. Regarding implant prostheses, the main factors influencing patient satisfaction are status of the prosthesis, type of retention system, complaints about the mouth, existence of oral pain, and chewing difficulties ${ }^{43}$. In a study regarding wearers of cement-retained implant-supported restorations, the total score of QoLIP-10 was significantly lower in those who complained about their mouths. Therefore, it was found that having complaints about the mouth is a direct predictor of patient satisfaction ${ }^{43,61}$. However, most patients do not complain about their mouths $(77.9 \%)$ and do not perceive the need for dental treatment $(86.3 \%)^{36}$. Regardless, patients who perceive the need for treatment have lower scores on the QoLIP-10 questionnaires $^{43,58,59}$. 
Prosthesis survival is defined as the prosthesis being present and functional at the time of assessment. Complications are defined as any event that requires additional treatment, and complications can be either biologic or technical ${ }^{79}$. For patients experiencing complications with single tooth restorations, a difference in OHRQoL was evident with an experience of a complication, the magnitude of the complication, and the frequency. Those with major complications tend to have a significantly higher OHIP, meaning lower quality of life, than those who experience minor complications ${ }^{10}$. Likewise, multiple complications are associated with a significantly lower quality of life, or a higher OHIP score ${ }^{10}$. It can be concluded that complications do significantly affect quality of life. Also, women tend to score higher on the OHIP scale, indicating they experience lower quality of life ${ }^{61}$. The profile of subjects reporting the highest psychological discomfort was a single woman having basic or special education in a study assessing quality of life in cement-retained implant prostheses ${ }^{61}$. In many studies, it has been found that single patients tend to express poorer overall satisfaction than those who are married ${ }^{36,61,111}$. In conclusion, the single female experiencing multiple complications experiences the lowest quality of life, according to these studies.

Implants offer the greatest benefit in patients with an anterior missing tooth with a statistically significant difference in QoL following treatment with an implant-supported crown $^{63}$. A case-control study was performed with subjects who had received either implant-supported crowns (ISC) or cantilevered resin-bonded bridges (cRBB) with at least 5 years of service. The results of the study showed patients who received either an ISC or cRBB have similar OHRQoL as assessed by OHIP. The study also examined any complications and their effect on OHRQoL. Differences in OHRQoL were evident with respect to experience of complications. Both the magnitude of complications and frequency of complications showed statistical significance. The magnitude of difference and the absolute difference in summary scores was greater among the ISC group than the cRBB group. This may be due to higher expectation from implant treatment than from conventional prostheses ${ }^{10}$. As shown in other studies, patients' expectation is associated with actual patient reported outcomes of treatment ${ }^{10,41,42}$.

Since complete denture qualities have a serious impact on denture satisfaction and 
quality of life, it is assumed that edentulous patients with good quality complete dentures would be satisfied with these dentures and have limited eating difficulties ${ }^{16}$. However, as stated above, there are maladaptive responses to complete dentures regardless of clinical perfection. These include patients who can adapt physically but not emotionally, patients who cannot adapt physically nor emotionally, and patients who cannot and do not wear dentures and who isolate themselves from society ${ }^{20,112,113}$. Implants have helped to alleviate some of these issues. Evidence has mostly been found for implant-retained overdentures in the mandible ${ }^{9,10}$. Several randomized controlled trials have been carried out to assess the impact of mandibular 2-implant overdentures and conventional dentures. Reports from these studies indicate that patients who received mandibular 2-implant overdentures were significantly more satisfied and reported significant improvements in their oral health-related quality of life than those who received conventional dentures $^{30,114}$. In a study by Awad et al. ${ }^{114}$, at 6 months post-treatment, patients with 2implant mandibular overdentures were significantly more satisfied with their ability to chew, stability in the denture, ability to speak, and overall satisfaction compared to those with conventional dentures. Implant-retained overdentures also have very satisfactory success rates ${ }^{92,115-118}$.

Overdentures and hybrids differ in their shapes, construction, principles, and biomechanics, which require some specific indicators of quality of life ${ }^{43}$. However, in a study by Zani et al. ${ }^{30}$, they have been grouped together in questionnaires because no statistic difference has been found between the two concerning acrylic teeth, bars, or occlusion. In a study by Preciado et al. $^{43}$, the QoLIP-10 total was significantly lower in participants who were required to replace their prosthesis and who had Locators as attachments. It has been found that bars provide higher comfort, greater stability, and better chewing efficiency than Locator attachments $\mathrm{do}^{43}$. For the majority, most patients are satisfied with esthetics $(87.3 \%)$, chewing (84\%), and prosthesis $(81.3 \%)$ in a study evaluating the quality of life for patients with implant-retained overdentures and hybrid prostheses $^{43}$. In the overdenture group, $33.3 \%$ reported one or more complaints, and $60 \%$ reported one or more complaints in the fixed group ${ }^{30}$. As stated above, complaints are associated with lower quality of life. Therefore, those with hybrids experience greater 
quality of life. In a study comparing fixed implant-supported prostheses, removable implant-retained prostheses, and complete dentures, $95.9 \%$ of fixed prostheses wearers and $97 \%$ of overdenture wearers were satisfied with chewing function ${ }^{57}$.

In terms of general satisfaction, only $36 \%$ of overdenture wearers and $46 \%$ of hybrid prostheses wearers were satisfied in a study by Martin-Ares et al. ${ }^{119}$. All studies have shown hybrid prostheses as offering the greatest quality of life because they offer better stability and facility for eating hard food ${ }^{43}$. Moreover, satisfaction has increased when patients with well-made dentures switch to hybrid prostheses ${ }^{79}$. Fixed detachables have increased satisfaction, more comfort, and patients can masticate food more efficiently ${ }^{94}$. However, hybrid prostheses wearers have reported the lowest quality of life in the dental facial esthetics category and performance domains. The lowest scores recorded in this study included the questions regarding prostheses appearance, the realism of the prosthesis, and satisfaction with the smile, speaking difficulties, and oral hygiene difficulties ${ }^{36}$. According to the QoLIP-10 questionnaire responses in this study, by Preciado $e t a l .^{36}$, hybrid prostheses negatively affected OHRQoL, in terms of the patients' self-perceived esthetics and functionality.

In a study by Zani $e t$ al. ${ }^{30}$, there was no statistically significant difference between patients who did not report complaints and those who reported one or more complaints on the OHIP scale in terms of the technical condition of the overdenture or hybrid prostheses. The technical conditions considered in this study were adaptation of base, occlusion, retention, and stability ${ }^{30}$. However, potential problems such as plaque accumulation, mucositis, peri-implantitis or fracture of the acrylic may affect the OHRQoL $^{95}$. Moreover, esthetic deficiencies or biomechanical failures may impair patient satisfaction ${ }^{120}$. In a study by Yunus et al. ${ }^{121}$ regarding patients receiving either implant fixed partial prostheses or overdentures, it was found that both groups improved their QoL following treatment, with fixed patients received the greatest benefit in QoL. Further analysis revealed after 3 months, posttreatment improvements in QoL were dependent on the pretreatment QoL. Improvements after 1 year were dependent on both the pretreatment QoL and the treatment provided. Therefore, it can be concluded that the patient's situation prior to treatment is important in determining clinical success ${ }^{121}$. These 
studies have proven that patient reported outcomes significantly affect clinical treatment success, and complications can negatively affect patients' quality of life.

While there is much evidence regarding the survival and complication rates of implant-supported crowns, there is limited evidence regarding the effect of rehabilitating bounded single tooth spaces ${ }^{120}$. Moreover, there is a substantial amount of evidence demonstrating the impact of mandibular implant overdentures ${ }^{43}$, but these studies have not assessed if satisfaction with the prosthesis can be affected by complications. Lastly, fixed detachables have been studied using the QoLIP-10 questionnaire ${ }^{36}$, and patients' quality of life has been affected post-treatment. However, these studies failed to mention if these patients had undergone complications with their prostheses, resulting in perceived decreased quality of life. The current study aims to address these concerns and explore the differences in quality of life among those who experience complications and those who do not. 


\section{Chapter III:}

\section{MATERIALS AND METHODS}

\section{Sample}

The main sample was composed of 467 patients whose names and addresses were retrieved from electronic health records (axiUm® Dental Software, Coquitlam, BC, Canada) at West Virginia University School of Dentistry in the dental student or specialty resident clinics using specific dental treatment codes, including implant overdentures (D6110, D6111), hybrids (D6114, D6115), and implant-supported crowns (D6058, D6059, D6060, D6061, D6062, D6063, D6064, D6094, D6064, D6066, D6067). All patients, aged 18 or older, who underwent treatment from January 1, 2010 to December 31, 2014 with these specific codes were mailed a survey containing the QoLIP-10 questionnaire. A stamped return envelope was provided. All responses were anonymous, and complications were self-reported.

This study was approved by the Institutional Review Board of West Virginia University for review of these subjects (IRB \#1505698140). All participants were given the option of not responding to the survey or skipping questions that they do not wish to answer. By answering the questions and mailing the survey back to the school, the patients were giving consent to be part of the research project. All information was kept confidential and no information provided could lead back to the subject's identity as a participant, and no inducement was provided for a response.

\section{Clinical Parameters}

Subjects treated with implant-retained overdentures or hybrid prostheses were asked to answer the same questionnaire, while implant-supported crown wearers filled out a separate questionnaire. Complications were self-reported for each questionnaire and treatment. Implant-retained overdenture and fixed detachable wearers were provided with pictures for clarification and yes/no questions for complications (Fig. 1a). 


\section{Implant-retained overdenture and fixed detachable wearers}
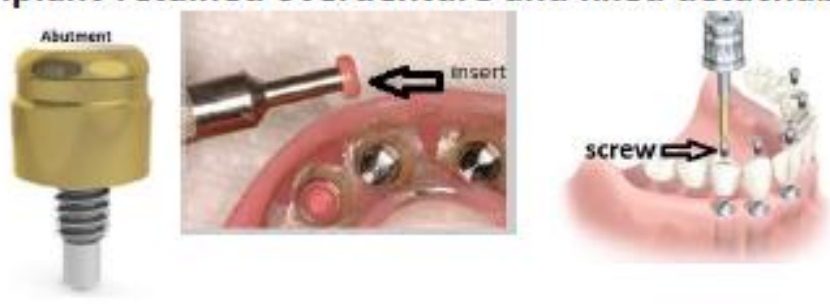

Please circle yes or no:

1. Have you had an abutment come loose? YES NO

2. Have you needed to have an insert replaced more than once a year? YES NO

3. Have you had the prosthesis replaced in the last 5 years? YES NO

4. Have you had to have your denture repaired (cracked, loose tooth, etc.)? YES NO

5. Have you ever had a screw come loose?

YES NO

Figure 1a. Illustrations and self-reported complications questions for implant-retained overdenture and fixed detachable wearers.

Implant crown prosthesis wearers were also provided with pictures for clarification and yes/no questions regarding any complications experienced (Fig. 1b).

\section{Implant crown prosthesis wearers

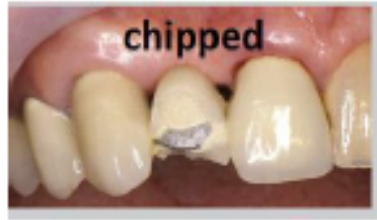

Please circle yes or no:

1. Has the crown ever come loose? YES NO

2. Has the crown ever chipped? YES NO

3. Has the crown needed to be replaced in the past 5 years? YES NO

4. Has the crown needed to be adjusted more than twice? YES NO

Figure 1b. Illustrations and self-reported complications questions for implant crown prosthesis wearers.

If the participant circled at least one "YES," the patient was grouped in the "Complications" category. No complication is considered a success, a minor complication is considered survived but not success, and a major complication is considered a failure ${ }^{10}$. A major complication would be if the prosthesis needed to be replaced in the past 5 years. 
Subjects' particulars including gender, age, marital status, and education level were recorded (Fig. 2).

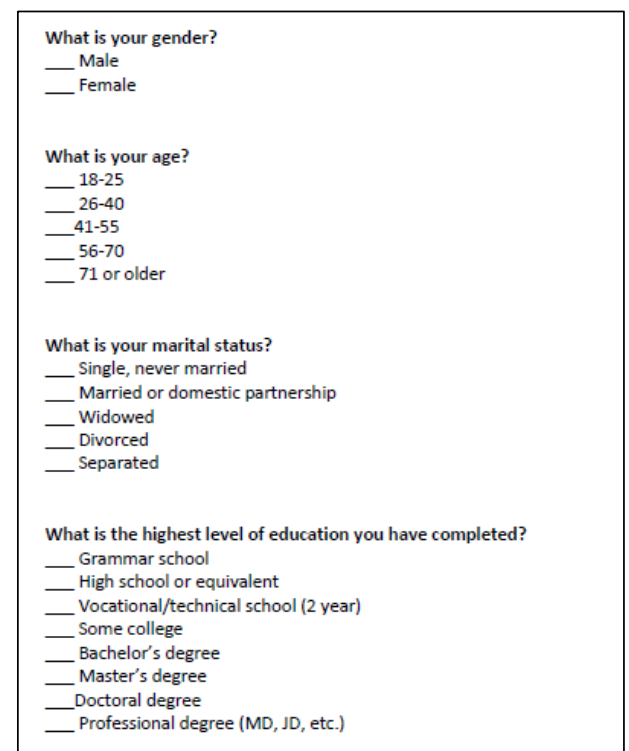

Figure 2. Demographic questions from survey.

\section{Oral Health-Related Quality of Life}

Oral health-related quality of life was assessed using the Quality of Life with Implant- Prostheses (QoLIP-10). This questionnaire has been validated for implantretained overdenture and hybrid prostheses wearers and also for implant crown prosthesis wearers previously ${ }^{36,43,61}$. Subjects filled out the QoLIP-10 with implant-retained overdenture and hybrid prostheses being in one group and implant crown prostheses being in another. The questions for all prostheses, however, were all the same (Fig. 3). They were separated for data analysis purposes. QoLIP-10 assesses the patients' biopsychosocial dimension, containing Items 1-5 (oral pain, chewing difficulty, worry/concern, communication/social relations, and activities of daily living, respectively). The second factor, called dental-facial aesthetics dimension, comprises Items 6-8 (satisfaction with the prosthesis's appearance, satisfaction with the realism of the prosthesis, and satisfaction with the smile, respectively). The third factor, designated as performance dimension, includes Items 9 and 10 (speaking difficulty or restrictions 
and oral hygiene difficulty, respectively).

Please indicate your level of agreement with the following statements and give the appropriate score in each case:

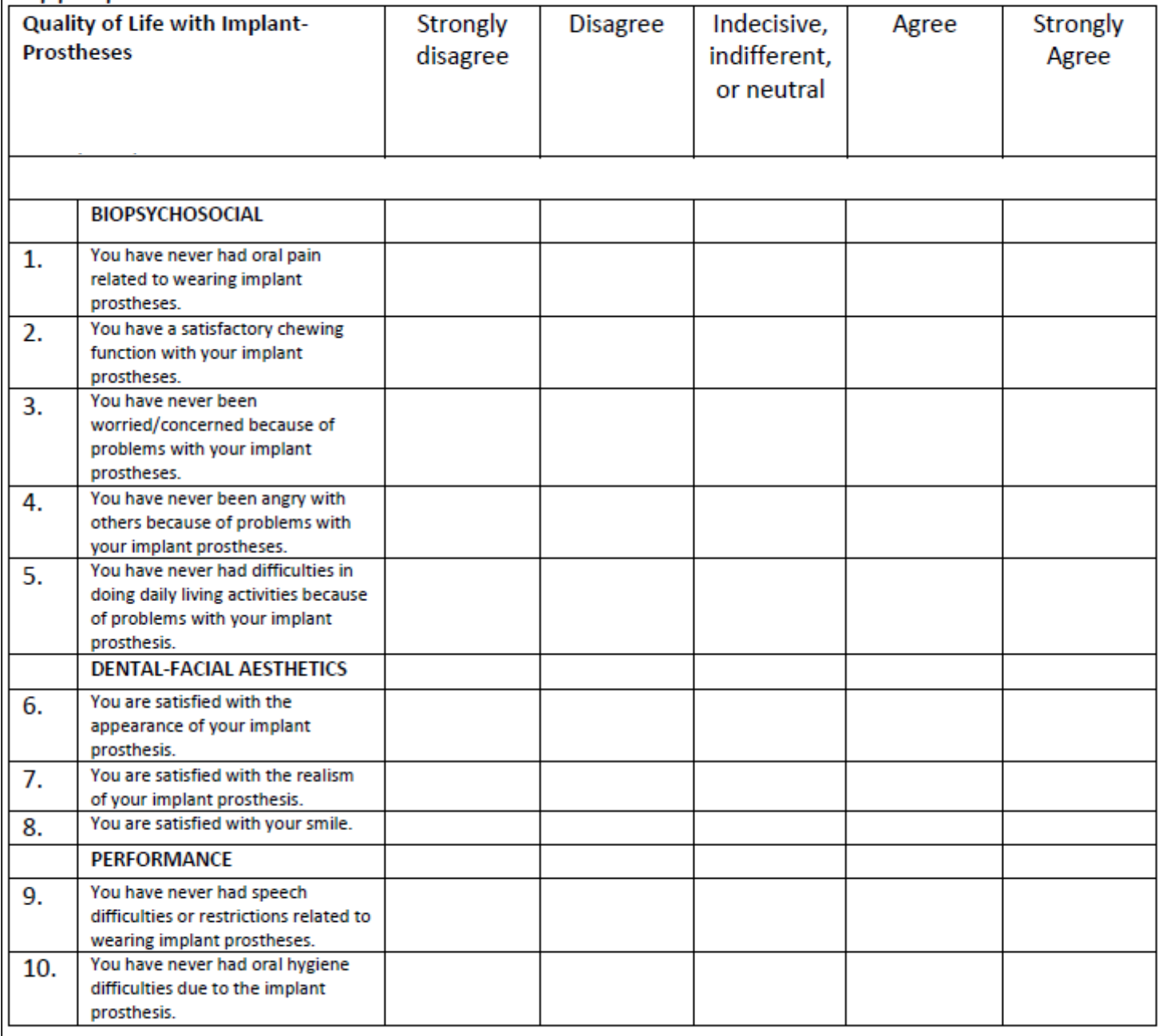

Figure 3. QoLIP-10 questionnaire.

The responses of the QoLIP-10 are intuitive and expressed on a Likert-type scale with proportional codes for the degrees of impact. Items valued at $<0$ have a negative effect, while values evaluated as +1 or +2 represent the positive side of each item. The total or summary score was the sum of different item scores, so that negative and positive values contributed to the total net score. The higher the summary score is, the higher the satisfaction of the patient is ${ }^{61}$.

One investigator gathered all surveys and collected data for any responses 
returned within a 3-month time period. To ensure the clinical staff had no access the patients' responses, the completed forms were placed in sealed envelopes.

\section{Statistical Analysis}

The data consists of recorded responses ranging from -2 to +2 for each survey question, with total scores ranging from -20 to +20 . The additive method (-ADD) ${ }^{122}$ was used for the QoLIP-10 analysis by adding the item codes at the appropriate frequency. Average scores were computed for complications and no complications, and averages were also computed for crown satisfaction scores and fixed detachable or removable overdenture scores. The data was broken down even further to evaluate any differences in the averages of specific survey questions. Averages were computed for each survey question under each category. The averages were used for comparison between and within test variables and can be interpreted as the higher the average, the greater the quality of life. The sociodemographic data were also evaluated for significance. Sociodemographic data were divided as follows: Gender (Male and Female), Marital Status (Single, Married, Divorced, and Widowed), Highest level of Education (High school and Some College), and Age ( $<56$ years and $\geq 56$ years).

The averages were compared using a one-way ANOVA to compare the effect of complications or sociodemographic data on patients' satisfaction. The variables showing significance were further evaluated using a post-hoc Tukey-Kramer Honestly Significant Difference (Tukey-Kramer HSD) to assess differences between pairs of means. The statistic software used to evaluate the data was JMP® Pro Version 12 (Cary, NC). 


\section{Chapter IV}

\section{RESULTS}

A total of 467 surveys were sent out, and a response of 176 surveys was returned, which constituted $38 \%$. All of the data were collected and processed as explained below, according to statistical methods used in related research. Of the 176 responses, 141 were from patients with implant supported crowns, and 35 were from the fixed-removable group. 51 complications were reported for the implant supported crown group and 27 in the implant supported overdenture or hybrid group. The frequencies of each complication, sometimes more than one in each patient, can be seen in Tables 1a and 1b, with the most common complications being loose crowns and the prostheses need to be repaired, respectively.

Table 1a. Frequencies of complications with implant-supported crowns. $(\mathbf{N}=51)$

\begin{tabular}{|l|r|}
\hline Variables & Number \\
\hline The crown has come loose & 24 \\
\hline The crown has been chipped & 14 \\
\hline $\begin{array}{l}\text { The crown has been replaced in the } \\
\text { last 5 years }\end{array}$ \\
\hline $\begin{array}{l}\text { The crown has needed to be } \\
\text { adjusted more than once }\end{array}$ \\
\hline
\end{tabular}

Table 1b. Frequencies of complications with implant-retained overdentures or hybrid prostheses.

$(\mathrm{N}=\mathbf{2 7})$

\begin{tabular}{|l|r|}
\hline Variables & Number \\
\hline The abutment has come loose & 7 \\
\hline $\begin{array}{l}\text { The insert has needed to be replaced } \\
\text { more than once a year }\end{array}$ & 2 \\
\hline $\begin{array}{l}\text { The prosthesis has been replaced in } \\
\text { the last 5 years }\end{array}$ & 6 \\
\hline $\begin{array}{l}\text { The prosthesis has needed to be } \\
\text { repaired }\end{array}$ & 9 \\
\hline A screw has come loose & 3 \\
\hline
\end{tabular}


Averaged QoL scores can be seen in Figure 4 as a function of the presence or absence of complications. Statistically significant differences of scores were seen between those who experienced complications and those who did not. Averaged scores can be seen in Figure 5 as a function of the type of prostheses. When evaluating the averaged scores between prostheses type, no significant difference was found (Table 2).

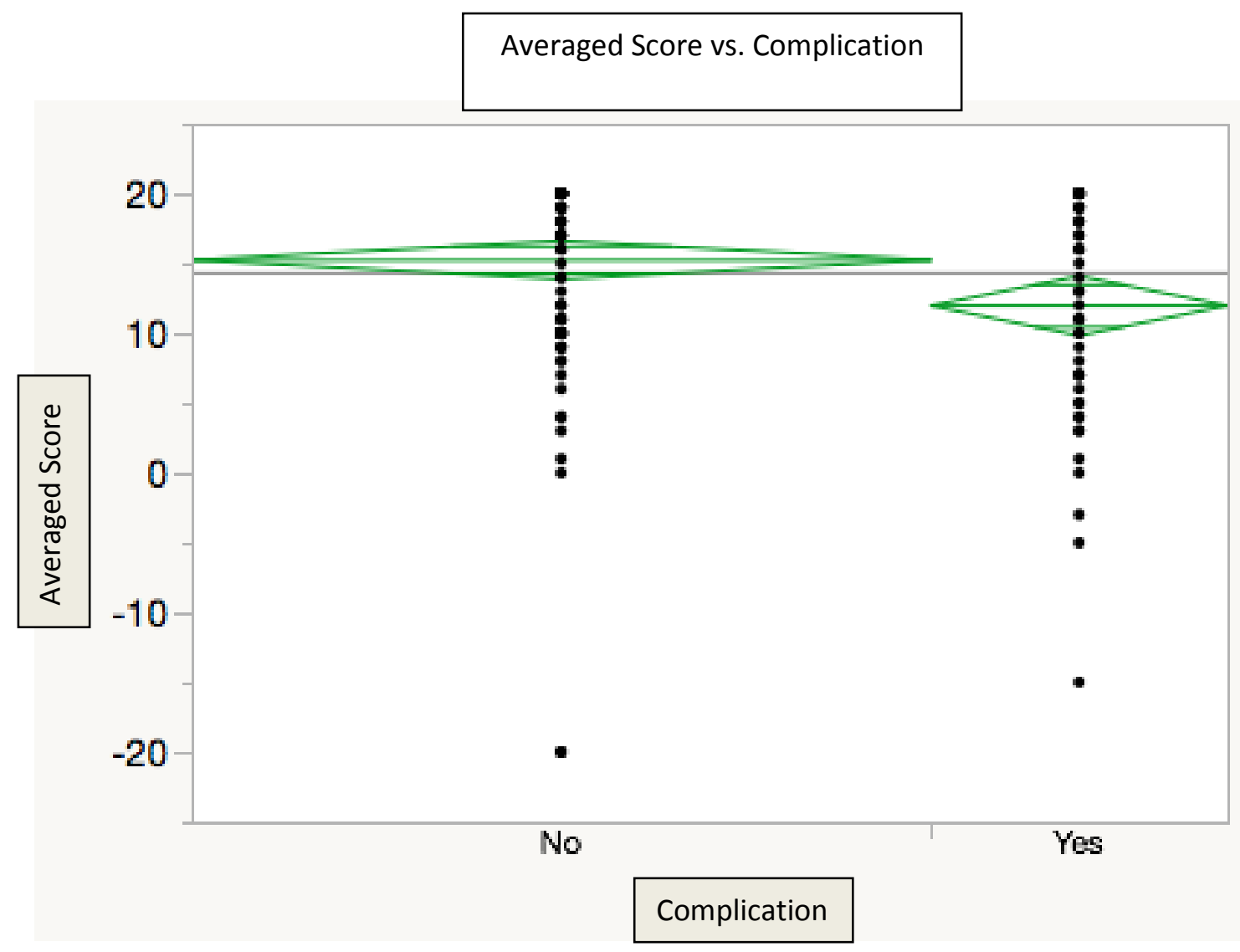

Figure 4. One way Analysis of Averaged Score by the Presence or Absence of Complications (JMP/Pro Ver12, SAS Inst. Inc., Cary, NC). 


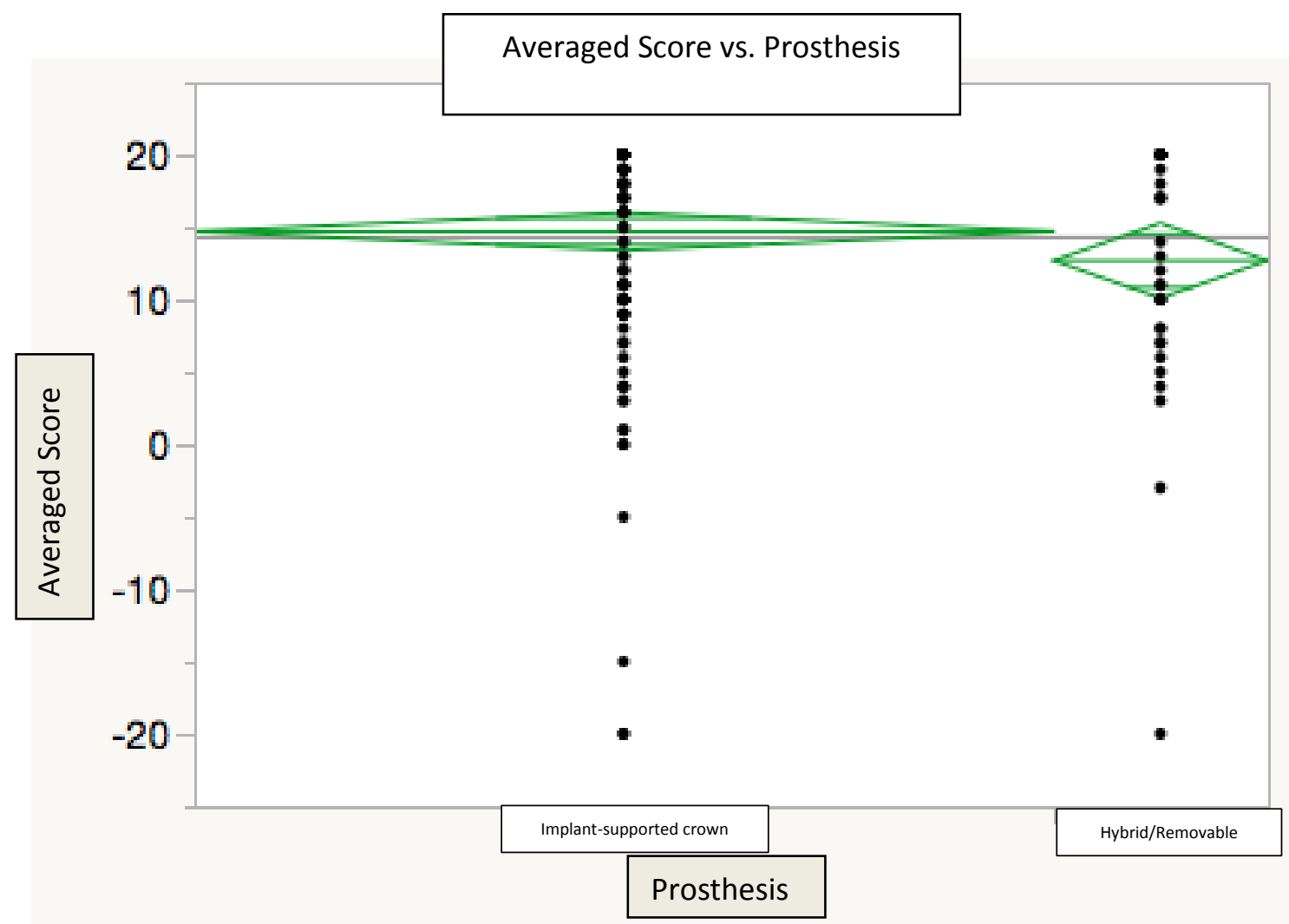

Figure 5. One-way Analysis of Averaged Score by the type of Prosthesis (JMP/Pro Ver12, SAS Inst. Inc., Cary, NC).

Table 2. One-way ANOVA of averaged scores between type of prosthesis.

\begin{tabular}{|l|r|r|r|r|r|}
\hline Variables & Number & Mean & DF & F Ratio & Prob > F \\
\hline Complication & 78 & 11.96 & 1 & 6.48 & $0.0118^{\mathrm{a}}$ \\
\hline $\begin{array}{l}\text { No Complication } \\
\text { crown }\end{array}$ & 98 & 15.23 & & & \\
\hline Hybrid/Removable & 35 & 14.70 & 1 & 1.88 & 0.1725 \\
\hline
\end{tabular}

${ }^{a}$ Represents significant differences at the $\mathrm{P}<0.05$ interval (JMP/Pro Ver12, SAS Inst. Inc., Cary, NC).

To define significance in regards to presence or absence of complication, a breakdown of the survey questions was evaluated. Averaged scores for each question were computed in the categories as follows: Crowns with complications, Crowns with no complications, Hybrid/Removable with complications, Hybrid/Removable without 
complications (Figure 6). Factor analysis of the QoLIP-10 index for implant prostheses wearers is outlined in Table 3.

Table 3. Factor analysis of the QoLIP-10 index for implant prostheses wearers. $(\mathbf{N}=\mathbf{1 7 6})$

\begin{tabular}{|c|c|c|c|c|}
\hline Items' mean scores & $\begin{array}{l}\text { Crowns with no } \\
\text { Complication }\end{array}$ & $\begin{array}{l}\text { Crowns with } \\
\text { Complication }\end{array}$ & $\begin{array}{l}\text { Hybrid/Removable with no } \\
\text { Complication }\end{array}$ & $\begin{array}{l}\text { Hybrid/Removable with } \\
\text { Complication }\end{array}$ \\
\hline Oral Pain & 1.58 & 1.21 & 1.78 & 1.24 \\
\hline Chewing Difficulty & 1.67 & 1.41 & 1.72 & 1.18 \\
\hline Worry/ concern & 1.47 & 0.94 & 1.56 & $.35^{\mathrm{a}}$ \\
\hline $\begin{array}{r}\text { Communication/social } \\
\text { relations }\end{array}$ & 1.62 & 1.06 & 1.83 & 1.06 \\
\hline Activities of daily living & 1.71 & 1.29 & 1.78 & 1.12 \\
\hline Satisfied with appearance & 1.72 & 1.59 & 1.78 & 1.47 \\
\hline Satisfied with realism & 1.69 & 1.44 & 1.83 & 1.41 \\
\hline Satisfied with smile & 1.61 & 1.5 & 1.78 & 1.29 \\
\hline Speaking difficulty & 1.7 & 1.26 & 1.67 & 0.76 \\
\hline Oral hygiene difficulty & $1.30^{\mathrm{a}}$ & 1.03 & 1.72 & 0.76 \\
\hline
\end{tabular}

${ }^{\text {a }}$ Represents significant differences at the $\mathrm{P}<0.05$ interval (JMP/Pro Ver12, SAS Inst. Inc., Cary, NC). 


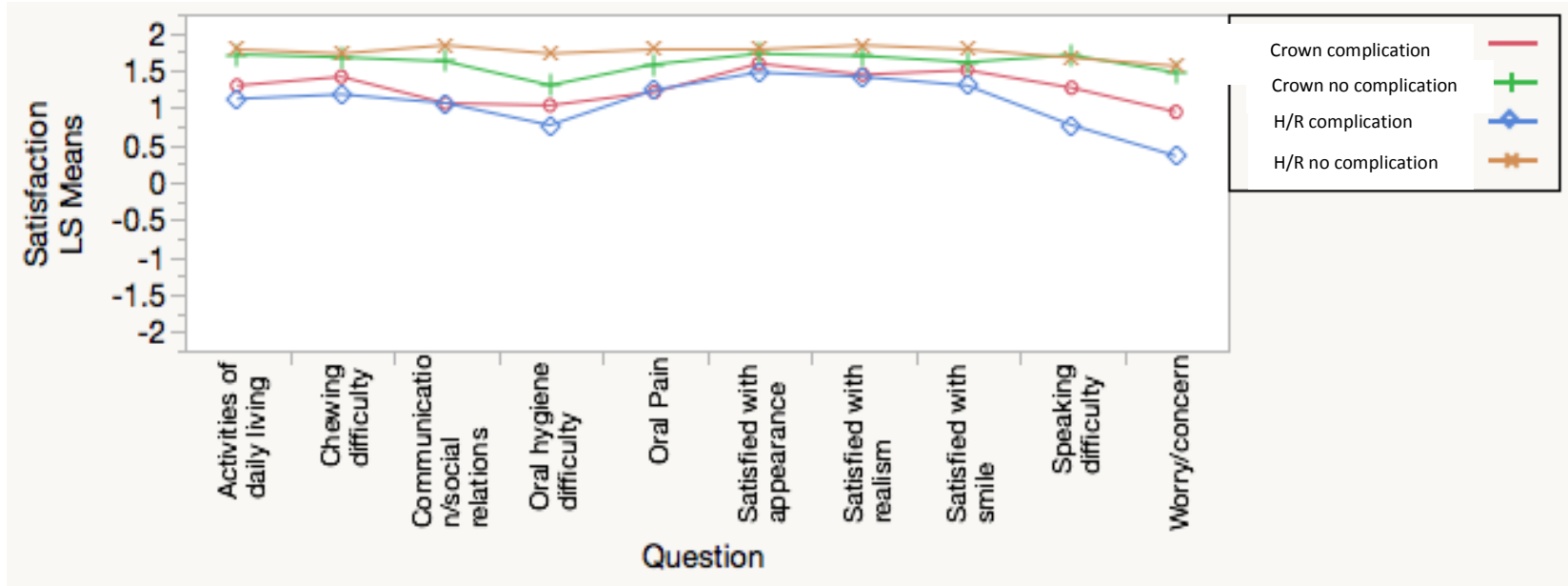

Figure 6. Averaged satisfaction scores by question (JMP/Pro Ver12, SAS Inst. Inc., Cary, NC).

Significant differences among averaged question scores were found for implantsupported crowns without complications and for hybrid or implant-retained overdenture prostheses wearers with complications (Table 4).

Table 4. One-way ANOVA among averaged question scores.

\begin{tabular}{|c|c|c|c|}
\hline Source & Number & F Ratio & Prob $>$ F \\
\hline Crowns with no Complication & 90 & 3.97 & $0.0001^{\mathrm{a}}$ \\
\hline Crowns with Complication & 51 & 1.17 & .31 \\
\hline $\begin{array}{l}\text { Hybrid/Removable with no } \\
\text { Complication }\end{array}$ & 8 & .44 & .91 \\
\hline $\begin{array}{l}\text { Hybrid/Removable with } \\
\text { Complication }\end{array}$ & 27 & 2.04 & $.038^{\mathrm{a}}$ \\
\hline
\end{tabular}

To define the significance among the different questions for implant-supported crowns with no complications (Table 5) and implant-retained overdenture and hybrid prostheses wearers with complications (Table 6), a Tukey-Kramer HSD was completed. A one-way ANOVA analysis confirmed patients are significantly less satisfied due to oral hygiene difficulty with implant-supported crown prostheses with no complications. 
Also, patients are significantly less satisfied due to worry or concern regarding problems with their implant-retained overdenture and hybrid prostheses. The remaining questions, however, did not show any significant differences.

Table 5. Tukey-Kramer HSD defining significance among questions for implant-retained crowns with no complications.

Connecting Letters Report

\section{Level}

Satisfied with appearance

A

Activities of daily living

A

Speaking difficulty

A

Satisfied with realism

A

Chewing difficulty

A

Communication/social relations

Satisfied with smile

A

Oral Pain

A

Worry/concern

A $B$

Oral hygiene difficulty

A B

Levels not connected by same letter are significantly different.

(JMP/Pro Ver12, SAS Inst. Inc., Cary, NC).

Table 6. Tukey-Kramer HSD defining significance among questions for implant-retained overdenture and hybrid prostheses wearers with complications.

\section{Connecting Letters Report}

Level

Satisfied with appearance

A

Satisfied with realism

A B

Satisfied with smile

A $\quad$ B

Oral Pain

A $\quad$ B

Chewing difficulty

A $\mathrm{B}$

Activities of daily living

A $\mathrm{B}$

Communication/social relations

A $\mathrm{B}$

Oral hygiene difficulty

A $\quad$ B

Speaking difficulty

A $\mathrm{B}$

Worry/concern

$\mathrm{B}$

Levels not connected by same letter are significantly different.

(JMP/Pro Ver12, SAS Inst. Inc., Cary, NC). 
The sociodemographic factors were evaluated using a one-way ANOVA test (Table 7). Significant differences were found among males' and females' quality of life averaged scores, and widowed persons' averaged scores among marital status reports. No significant differences were found with averaged scores comparing age or education.

Table 7. One-way ANOVA evaluating means of scores and statistical significance by sociodemographic factors.

\begin{tabular}{|c|c|c|c|c|c|}
\hline $\begin{array}{l}\text { Sociodemographic } \\
\text { factors }\end{array}$ & & Number & $\begin{array}{r}\text { QoL } \\
\text { score }\end{array}$ & F ratio & Prob $>$ F \\
\hline \multirow[t]{2}{*}{ Gender } & Males & 82 & 15.98 & \multirow[b]{2}{*}{8.66} & \multirow[b]{2}{*}{$0.0037^{\mathrm{a}}$} \\
\hline & Females & 89 & 12.52 & & \\
\hline \multirow{4}{*}{ Marital Status } & Divorced & 15 & 18.93 & \multirow{4}{*}{4.49} & \multirow{4}{*}{$0.0047^{\mathrm{a}}$} \\
\hline & Married & 128 & 14.28 & & \\
\hline & Single & 7 & 15.58 & & \\
\hline & Widowed & 21 & 9.67 & & \\
\hline \multirow[t]{2}{*}{ Highest Education } & High School & 38 & 12.95 & \multirow[b]{2}{*}{1.20} & \multirow[b]{2}{*}{0.3024} \\
\hline & Some college & 126 & 14.35 & & \\
\hline \multirow[t]{2}{*}{ Age } & $<56$ years old & 21 & 14.05 & \multirow[b]{2}{*}{0.01} & \multirow[b]{2}{*}{0.9368} \\
\hline & $\geq 56$ years old & 150 & 14.19 & & \\
\hline
\end{tabular}

${ }^{a}$ Represents significant differences at the $\mathrm{P}<0.05$ interval (JMP/Pro Ver12, SAS Inst. Inc., Cary, NC).

Table 8 illustrates the trend towards widowed persons having significantly lower scores compared specifically with divorced persons. Females were further evaluated by separating and comparing the categories of those experiencing complications and those not experiencing complications with their implant prostheses. When doing so, there was no significant difference found among scores of those with or without complications (Table 9). 
Table 8. Tukey-Kramer HSD defining significance among averaged scores based on marital status. Connecting Letters Report

Level

Divorced A

Single A B

Married A B

Widowed

Levels not connected by same letter are significantly different.

(JMP/Pro Ver12, SAS Inst. Inc., Cary, NC).

Table 9. One-way ANOVA evaluating females with and without complications.

\begin{tabular}{|l|r|r|r|}
\hline Source & Number & F Ratio & Prob > F \\
\hline $\begin{array}{l}\text { Females with no } \\
\text { Complication }\end{array}$ & 62 & 3.28 & 0.0734 \\
\hline Females with Complication & 27 & & \\
\hline
\end{tabular}

${ }^{a}$ Represents significant differences at the $\mathrm{P}<0.05$ interval (JMP/Pro Ver12, SAS Inst. Inc., Cary, NC). 


\section{Chapter V}

\section{DISCUSSION}

The present study investigated the differences in implant patient satisfaction among those experiencing complications and those who have not. Based on the results, the null hypothesis that presence of complications will not have an effect on oral healthrelated quality of life was rejected. Similarly, the null hypothesis that the quality of life of implant prostheses wearers does not depend on socio-demographic factors was rejected for certain factors including gender and marital status. It was accepted with regards to age and education socio-demographic factors. Patients experiencing complications were in general less satisfied compared to patients who did not experience complications with their implant prostheses. However, when evaluating the average scores between prostheses type, no significant difference was found.

A total of 51 of $141(36.2 \%)$ patients with implant-supported crowns experienced complications, which is a higher percentage when comparing to other studies. Of the possible complications of loose crown, chipped crown, replaced crown, and need for a crown adjustment, the most common complication was loose crowns (47\%), followed by chipped crowns (27.5\%). A loose crown could include screw loosening or loss of retention of the implant-supported crown. Therefore, these findings are in agreement with many other studies indicating screw loosening and loss of retention as the most common complications with implant-supported crowns ${ }^{11,70-76}$. Similarly, chipped crowns or veneer fracture have been reported as the second most common complication ${ }^{11,62}$. It has been suggested that veneer fracturing could be more common in screw-retained implant crowns due to the resistance of veneering material around screw access holes ${ }^{36}$. This is something worth considering when evaluating occlusion and location of the screw access hole. In these situations, a cemented restoration could be indicated. In a study by Brägger

et al. ${ }^{11}$, it was found that screw loosening did not increase the risk of prosthesis failure. However, porcelain or veneer fracture was more likely to result in prosthesis failure ${ }^{11}$. Therefore, even though veneer fracture is not the most common complication, it is the 
most deleterious complication that can occur.

Interestingly, while there were no significant differences among the average scores for each survey question for patients with complications, there was a significant difference for implant-supported crown patients with no complications. Patients were significantly less satisfied due to oral hygiene difficulties when experiencing no technical complications with the implant-supported crown prosthesis. This suggests that although the patient does not experience technical complications, a decrease in quality of life can be experienced due to oral hygiene troubles, including food impaction and difficulty cleaning and flossing around the implant prosthesis. However, there were no particular factors in patients experiencing complications that caused a statistically significant decrease in quality of life for the patient. It is important for practitioners to realize that time should be taken for patients with implant-supported crowns and proper maintenance advice should be suggested as well. As shown here, this could help improve the patient's quality of life.

It has been shown in other studies that cantilever fixed partial dentures have similar survival rates after 5 years compared to implant-supported crowns ${ }^{62}$. In a study by Lam et al. ${ }^{10}$, cantilever fixed partial dentures had a higher success rate, especially with success of supporting structures, and there were fewer biological complications compared to implant-supported crowns. Similarly, Goodacre and associates reported a greater number of clinical complications associated with implant-supported crowns compared to tooth-supported crowns ${ }^{123,124}$. Therefore, if the practitioner wishes to avoid these complications and possible increased chair time, a cantilever fixed partial denture is an option and will offer a similar prosthetic life span.

A total of 27 out of $35(77 \%)$ patients with hybrid prostheses and implant overdentures experienced complications with their prostheses, which is also a higher percentage of complications, compared to other studies. There were no differences between implant-supported crowns and the hybrid/overdenture wearers with regard to patient satisfaction scores. There was a tendency for patients with overdentures and fixed implant prostheses to report lower satisfaction scores than those with implant-supported 
crowns. This could be due to the patient possessing higher expectations of more complex treatment with implants. The higher complication rate reported for these patients could be due to the way in which this study was carried out. Since the complications were selfreported, there is a chance that those who experienced complications were more inclined to respond to the survey compared to those who did not experience complications. This could have created skewed results. Of the possible self-reported complications of loose abutment, retentive insert needing to be replaced more than once a year, a need for the prosthesis to be replaced in the last 5 years, the prosthesis needing to be repaired, and screw loosening, the most common complication was the prosthesis needing to be repaired. The second most common complication was an abutment loosening. This is not in agreement with previous studies, which found loss of retention as the most frequent complication $^{65}$. In the current study, the complication of loss of retention would be equivalent to replacing the insert more than once a year. However, in terms of fixed detachables, previous studies are in agreement with the present study with veneer fracturing being the most common complication ${ }^{96}$. With the prosthesis needing to be repaired being reported as the most common complication in the present study, veneer fracturing could be considered under this category.

There were significant differences among average question scores for hybrid and overdenture prostheses wearers with complications in the category of worry/concern regarding problems with the prosthesis. The remaining questions did not show any significant differences. This is noteworthy because patients generally were unsatisfied and experienced lower quality of life since they were worried and concerned about the complication they had experienced. A previous study found that fixed detachable wearers reported better subjective health status compared to overdenture and conventional denture wearers ${ }^{57}$. It could be surmised that since these particular patients consider themselves in better general health, the same is expected of their oral health. This expectation could lead to worry and concern when complications occur. Also, patients who did not experience complications were not particularly worried about their prosthesis. This means if patients experience a complication, their quality of life is affected because of substantial worry and concern that the prosthesis may fail or another complication may 
be encountered in the future.

Evaluation of socio-demographic factors revealed females and widowed persons reporting lower quality of life than males and divorced, married, or single persons. However, age and education did not show any strong correlation with patients reporting less satisfaction. Yet, there was a trend towards patients having higher education and reporting increased satisfaction with their prostheses. Females did not show any difference in satisfaction when comparing those who experienced complications and those who did not. Therefore, in general, females reported lower satisfaction even if they did not experience any complications at all. This finding is not in agreement with another study reporting women having significantly higher OHIP scores, or lower satisfaction scores, compared with men among those experiencing complications ${ }^{10}$. However, it has been found in other studies that women, in general, are less satisfied than men with their prostheses $^{43,110}$. While some studies found marital status did not affect patient satisfaction $^{36}$, others found the opposite ${ }^{43}$. A study by Preciado et al. ${ }^{43}$ found those who were married were less satisfied with their overdentures and hybrids, and other studies found single persons documenting the lowest satisfaction rates with implant prostheses $^{36,111}$. These studies are all in disagreement with findings from the current study, which indicated a significantly lower satisfaction rate in widowed persons. This finding is consistent with a study correlating loneliness regarding marital status and quality of life, in which widowed persons reported feeling lonelier and having lower quality of life due to loss of a spouse. Those who lived with a partner were better able to adapt to poorer medical conditions than those who lost a partner ${ }^{125}$.

In terms of education, there was a trend in the present study toward patients with higher education reporting higher levels of satisfaction with their prostheses. This was supported by another study which found patients with a university education demonstrated significantly higher levels of satisfaction than did subjects with little or no education. This finding is also in agreement with public health research reporting a correlation between lower socioeconomic status and poor health ${ }^{36}$. Patients with higher education may understand more about function of prosthesis, implants, and their limitations, proper home care, and maintenance recalls. Age was also not a modulating 
factor of well-being in the present study, which agrees with other studies evaluating complete dentures and also implant prostheses ${ }^{36,111}$. This could perhaps be due to the geriatric population expectation that health declines with age ${ }^{15}$. However, in another study comparing conventional dentures, implant-supported overdentures, and implantsupported fixed prostheses, patient age and expectations were equally important for treatment success. In their study, older patients wanted less invasive and less costly treatment, which is an important consideration when initiating the patient's treatment $\operatorname{plan}^{119}$.

An advantage of the current study design compared to previous studies of quality of life surveys is the comparison of satisfaction rates among implant prostheses wearers experiencing complications. The utilization of self-reported complications on the survey allowed for an efficient method of administering and answering the surveys. Most studies have relied on patients coming to the dental office and the clinician reporting any clinical complications found in the mouth. The current method allowed for a more consistent data collection method and also surveyed a sample in a more concise and combined way than has been done before regarding implant prostheses. However, a downside to collecting data in this manner is the necessity to rely on patient memory to correctly identify the complication.

Patients do have higher expectations now than ever-before in terms of dental health ${ }^{114}$. It is thought that perhaps patients who want implants may have chosen this treatment because they anticipated an impact from this treatment on other aspects of their lives as well ${ }^{114}$. As seen in this study and in many others, complications can happen and are common. Complications can cause the patient to spend more time and money in the dental office, which has proven to result in patient dissatisfaction ${ }^{10}$. Other factors could also lead to patient dissatisfaction and poor perception of life quality. For example, subjects with high morale and self-image prove to be more accepting of dental treatment ${ }^{126}$. It is important to be able to recognize a dissatisfied patient and know how to deal with these patients and personalities. In a study by Quran et al. ${ }^{105}$, it was proven that patients with many complaints often have associated emotional problems and such patients are more difficult to satisfy with the treatment provided. Dissatisfied patients 
also experience negative moods and feelings and are usually less intellectual, less stable, more meticulous, and more self-centered ${ }^{105}$. Certain techniques have been recommended to handle patients who are dissatisfied. These include "Listen and Repeat," "Acknowledge the difficulty and focus on the positive," and "Set small, achievable goals and reward progress with praise and feedback ${ }^{24}$." Practicing these techniques with patients can help keep the patient calm and also more understanding when complications do occur. Educating patients about expectation of the restorations and realistic discussion of limitations and complications that may occur during treatment planning and posttreatment recalls are important for increasing patient satisfaction and decreasing anxiety and worries about complications.

One disadvantage of this study was having the survey questions regarding overdentures and hybrid prostheses in the same questionnaire. In this manner, it was impossible to observe any differences in quality of life between overdenture-wearers and hybrid prostheses-wearers. Even though previous studies have proven these prostheses can be merged into one questionnaire due to no significant differences in patient reports $^{43}$, it would have been interesting to evaluate patient satisfaction for the two very different prostheses. Similarly, another disadvantage of this study was failing to separate the self-reported complication questions for the overdenture and hybrid prostheses questionnaire. Results could have then assessed the frequency of complications for each prosthesis rather than the composite scores for both. These results could then have been more properly compared with previous studies reporting complications with these prostheses, individaully.

Moreover, the small sample size, specifically for the overdenture and hybrid group, recruitment of participants from a single university dental clinic, and failure of some subjects to answer all questions on the survey could have caused deviations in the results. This could have also caused a potential issue with the prostheses' representativeness. However, the minimum sample size was 35 , and previous studies have involved fewer than 30 subjects in one prosthetic group ${ }^{57}$. The findings can also be extrapolated to similar dental settings ${ }^{57}$. Also, since there was no time period mentioned for when complications occurred, there may have been some recall biases when patients 
filled out the survey and were asked to recollect their experiences. Lastly, the patients' responses and biases could have influenced the outcome, because the outcome was based on patients' evaluations for treatment. These disadvantages are all applicable to other similar studies and can consequently be associated ${ }^{57}$.

Edentulousness and partial edentulism lead to diminished chewing, nutritional imbalance, disability, handicap, and reduced quality of life ${ }^{57}$. Edentulism is common in the United States, and the number of edentulous and partially edentulous patients is everincreasing. The development of dental implants has helped many patients with comfort, esthetics, prosthesis stability and retention, verbal communication, and mastication. While much research has been focused on the success or failure of osseointegrated implants from a biological perspective, not many have addressed the prosthetic aspects or the perception of patient treatment success in terms of satisfaction ${ }^{30}$. As seen in this study and in others by many authors, success cannot be defined only by objective measures, because the practitioner's definition of treatment success and that of the patient are often very dissimilar. Research has proven that patients consider other factors when determining treatment outcome success ${ }^{57}$. Therefore, practitioners should consider the attitudes of their patients when choosing treatment options for them. These aspects can influence the oral health-related quality of life as well as clinical outcomes, and understanding patient issues helps clinicians provide the best treatment that matches patients' expectations ${ }^{57,127,128}$. When assessing rehabilitation treatments, the patients' opinions of treatment must be considered as a variable of treatment success ${ }^{129}$.

Many times, dental problems may fade to the background when other health problems exist in the elderly population ${ }^{111}$. Similarly, many older adults expect problems with dentures and oral pain and accept them without feeling a need for treatment ${ }^{15,20}$. Finances available for dental treatment can also deter some of the patients for seeking help with their dental problems. Ignoring symptoms can lead to more complications and even failures. Therefore, the question of "what does this problem stop you from doing?" should become an important component of the medical history ${ }^{15}$. Questionnaires have proven to be effective and helpful in recording the consequence and severity of oral problems on functional psychosocial well-being ${ }^{16}$. Also, patient-centered outcome 
measurement techniques have been useful in facilitating a more appropriate patientcentered solution ${ }^{111,120}$. Patient ratings on satisfaction are justified because the questionnaires are sensitive enough to capture clinical significant differences. However, some practitioners have reported patients over estimating their degree of satisfaction with treatment, creating a ceiling effect ${ }^{6,34}$.

Oral health-related quality of life characterizes an individual's perception of oral health and can be used an indicator of advantages of prosthodontic rehabilitation strategies ${ }^{120,130}$. Oral health-related quality of life is directed towards the influence of a therapy on the patient's health condition. Satisfaction is associated directly with that therapy ${ }^{34}$. Greater quality of life has been associated with more visits to the dentist and higher brushing frequencies. This indicates that practicing healthy habits and proper maintenance appointments can lead to treatment success ${ }^{43}$. Those who postpone treatment experience a greater negative social impact than those who have more regular care $^{15}$. Moreover, frequent appointments may help with lowering complication rates with prostheses. Experiencing complications can cause physical, social, and mental issues with poorer oral health-related quality of life $\mathrm{e}^{32}$. Those experiencing dissatisfaction may be doing so as a result of immediate or long-term expectations. Many patients believe implants will solve many of their prosthetic problems, and sometimes, this idea is a result of the dentist making assurances. It is important for the practitioner to educate the patient about implants, how complications can and may occur, and how to properly maintain them. The present study illustrates how complications can affect the patient's quality of life, and perhaps educating the patient ahead of time will aid in softening the impact if and when complications do occur. 


\section{Chapter VI:}

\section{SUMMARY}

Prosthetic rehabilitation of the dentition is not without technical complications, which lead to increased treatment time, cost, and a decrease in patient satisfaction. The use of questionnaires as a determinant for treatment success has proven to be useful for patient management and treatment planning. This study attempted to illustrate any differences in quality of life for patients experiencing complications with implant prostheses compared to those who have not. This study only provides data for hybrid prostheses, implant overdentures, and single implant crown prostheses. Findings include those experiencing technical complications with implant prostheses do have a lower quality of life than those who do not experience complications. Also, socio-demographic variables do affect quality of life, and the lowest quality of life has been reported by widowed females. The data does provide insight to practitioners for which factors affect patient satisfaction with certain implant prostheses and also how a patient's quality of life is affected as a result of technical complications.

\section{CONCLUSIONS}

1) Those experiencing technical complications with implant prostheses report a lower quality of life compared to those who have not had complications.

2) The most common complication with single implant crowns is loss of retention. The most common complication with hybrids and implant overdentures is the need for prosthesis repair.

3) Patients report lower quality of life due to oral hygiene difficulties in single implant crowns without complications.

4) Patients report lower quality of life due to worry or concern regarding complications with their hybrid or implant overdenture prostheses. 
5) Widowed and female persons report lower quality of life compared to those who are divorced, married, or single and male. 


\section{REFERENCES}

1. Thomason JM. The McGill consensus statement on overdentures. mandibular 2implant overdentures as first choice standard of care for edentulous patients. The European Journal of Prosthodontics and Restorative Dentistry. 2002;10(3):95-96.

2. Aglietta M, Siciliano V, Zwahlen M, et al. A systematic review of the survival and complication rates of implant supported fixed dental prostheses with cantilever extensions after an observation period of at least 5 years. Clinical Oral Implants Research. 2009;20:441-451.

3. Albrektsson T, Donos N. Implant survival and complications. the third EAO consensus conference 2012. Clinical Oral Implants Research. 2012;23(6):63-65.

4. Assuncão W, Zardo G, Delben J, Barão V. Comparing the efficacy of mandibular implant-retained overdentures and conventional dentures among elderly edentulous patients: Satisfaction and quality of life. Gerodontology. 2007;24:235-238.

5. Gaviria L, Salcido J, Guda T, Ong J. Current trends in dental implants. Journal of the Korean Association of Oral and Maxillofacial Surgeons. 2014;40(2):50-60.

6. Allen P, McMillan A, Locker D. An assessment of sensitivity to change of the oral health impact profile in a clinical trial. Community Dentistry and Oral Epidemiology. 2001;29:175-182.

7. Locker D, Jokovic A, Clarke M. Assessing the responsiveness of measures of oral 
health-related quality of life. Community Dentistry and Oral Epidemiology. 2004;32(1):10-18.

8. McGrath C, Comfort MB, Lo EC, Luo Y. Patient-centered outcome measures in oral surgery: Validity and sensitivity. British Journal of Oral and Maxillofacial Surgery. 2003;41:43--47.

9. Thomason JM, Heydecke G, Feine J, Ellis J. How do patients perceive the benefit of reconstructive dentistry with regard to oral health-related quality of life and patient satisfaction? A systematic review. Clinical Oral Implants Research. 2007;18(3):168-188.

10. Lam W, McGrath C, Botelho M. Impact of complications of single tooth restorations on oral health-related quality of life. Clinical Oral Implants Research. 2014;25(1):67-73.

11. Brägger U, Karoussis I, Persson R, Pjetursson B, Salvi G, Lang N. Technical and biological complications/failures with single crowns and fixed partial dentures on implants: A 10-year prospective cohort study. Clinical Oral Implants Research. 2005;16(3):326-334.

12. The glossary of prosthodontic terms. The Journal of Prosthetic Dentistry. 2005;94(1):10-92.

13. Zest Anchors. LOCATOR implant attachment quick reference guide. https://www.zestanchors.com/media/wysiwyg/pdf/locator/Locator_Implant_Attachment_ Quick_Reference_Guide.pdf. Updated 2016. Accessed 07/06, 2016.

14. Reisine S. The impact of dental conditions on social functioning and the quality of 
life. Annual Review of Public Health. 1988;9:1-19.

15. Gift H, Redford M. Oral health and the quality of life. Clinics in Geriatric Medicine. 1992;8(3):673-683.

16. Anastassiadou V, Heath M. The effect of denture quality attributes on satisfaction and eating difficulties. Gerodontology. 2006;23:23-32.

17. International classification of impairements, disabilities, and handicaps. World Health Organization: Geneva. 1980.

18. Liedberg B, Stoltze K, Owall B. The masticatory handicap of waering removable dentures in elderly men. Gerodontology. 2005;22(1):10-16.

19. Friske J, Davis D, Frances C, Gelbier S. The emotional effects of tooth loss in edentulous people. British Dental Journal. 1998;184(2):90-93.

20. Allen P, McMillan A. A review of the functional and psychosocial outcomes of edentulousness treated with complete replacement dentures. Journal of the Canadian Dental Association. 2003;69(10):662.

21. Strassburger C, Heydecke G, Kerschbaum T. Influence of prosthetic and implant thearpy on satisfaction and quality of life: A systematic literature review. part Icharacteristics of the studies. The International Journal of Prosthodontics. 2004;17(1):83-93.

22. Berg R, Hallauer D, Berk S. Neglected aspects of the quality of life. Health Services Research. 1976;11(4):391-395. 
23. Cushing A, Sheiham A, Maizels J. Developing socio-dental indicators- the social impact of dental disease. Community Dental Health. 1986;3(1):3-17.

24. Roessler D. Compelete denture success for patients and dentists. International Dental Journal. 2003;53:340-345.

25. Lechner S, Champion H, Tong T. Complete denture problem solving: A survey. Australian Dental Journal. 1995;40(6):377-380.

26. Hennessy C, Moriarty D, Zack M, Scherr P, Brackbill R. Measuring health-related quality of life for public health surveillance. Public Health Reports. 1994;109:665-672.

27. Slade G. Derivation and validation of a short-form oral health impact profile. Community Dentistry and Oral Epidemiology. 1997;25(4):284-290.

28. Gift H, Reisine S, Larach D. Social impact of oral diseases: Changes in normal activities, work and school patterns. Journal of Dental Research. 1991;70:429.

29. Pearlman R, Uhlmann R. Quality of life in elderly, chronically ill outpatients. Journal of Gerontology. 1991;46(2):31-38.

30. Zani S, Rivaldo E, Frasca L, Caye L. Oral health impact profile and prosthetic condition in edentulous patients rehabilitated with implant-supported overdentures and fixed prostheses. Journal of Oral Science. 2009;51(4):535-543.

31. de Bruyn H, Collaert B, Lindén U, Björn A. Patient's opinion and treatment outcome of fixed rehabilitation on brånemark implants. A 3-year follow-up study in private dental practices. Clinical Oral Implants Research. 1997;8(4):265-271. 
32. Carr A. Successful long-term treatment outcomes in the field of osseointegrated implants: Prosthodontic determinants. The International Journal of Prosthodontics. 1998;11(5):502-512.

33. Locker D. Patient-based assessment of the outcomes of implant therapy: A review of the literature. The International Journal of Prosthodontics. 1998;11:453-461.

34. Michaud P, de Grandmont P, Feine J, Emami E. Measuring patient-based outcomes: Is treatment satisfaction associated with oral health-related quality of life? J Dent. 2012;40(8):624-631.

35. Fitzpatrick R, Davey C, Buxton M. Evaluating patient-based outcome meaures for use in clinical trials. Health Technology Assessment. 1988;2(14):1-74.

36. Preciado A, Del Río J, Lynch C, Castillo-Oyagüe R. Impact of various screwed implant prostheses on oral health-related quality of life as measured with the QoLIP-10 and OHIP-14 scales: A cross-sectional study. Journal of Dentistry. 2013;41(12):11961207.

37. Brennan M, Houston F, O'Sullivan M, O'Connell B. Patient satisfaction and oral health-related quality of life outcomes of implant overdentures and fixed complete dentures. International Journal of Oral and Maxillofacial Implants. 2010;25(4):791-800.

38. Hertzog M. Considerations in determining sample size for pilot studies. Research in Nursing and Health. 2008;31(2):180-191.

39. Cronbach L. Coefficient alpha and the internal structure of tests. Psychometrika. 
1951;16:297-334.

40. Moynihan P, Elfeky A, Ellis J, Seal C, Hyland R, Thomason J. Do implant-supported dentures facilitate efficacy of eating more healthy? Journal of Dentistry. 2012;40(10):843-850.

41. Zhang M, McGrath C, Hägg U. Patients' expectations and experiences of fixed orthodontic appliance therapy. impact on quality of life. The Angle Orthodontist. 2007;77(2):318-322.

42. Lee T, McGrath C, Wong R, Rabie A. Patients' perceptions regarding microimplant as anchorage in orthodontics. The Angle Orthodontist. 2008;78(2):228-233.

43. Preciado A, Del Río J, Lynch C, Castillo-Oyagüe R. A new, short, specific questionnaire (QoLIP-10) for evaluating the oral health-related quality of life of implantretained overdenture and hybrid prosthesis wearers. J Dent. 2013;41(9):753-763. doi: http://dx.doi.org/10.1016/j.jdent.2013.06.014.

44. Locker D, Grushka M. Prevalence of oral and facial pain and discomfort: Preliminary results of a mail survey. Community Dentistry and Oral Epidemiology. 1987;15(3):169172.

45. Tsakos G, Allen P, Steele J, Locker D. Interpreting oral health-related quality of life data. Community Dentistry and Oral Epidemiology. 2012;40(3):193-200.

46. Guckes A, Smith D, Swoope C. Counseling and related factors influencing satisfaction with complete dentures. The Journal of Prosthetic Dentistry. 1978;39:259- 
47. Čelebić A, Knezović-Zltarić D, Papić M, et al. Factors related to patient satisfaction with complete denture therapy. The Journals of Gerontology. Series A, Biological Sciences and Medical Sciences. 2003;58(10):M948-953.

48. Veyrune J, Tubert-Jeannin S, Dutheil C, Riordan P. Impact of new prostheses on the oral health related quality of life of edentulous patients. Gerodontology. 2005;22(1):3-9.

49. Stewart A, Hays R, Ware JJ. The MOS short-form general health survey. reliability and validity in a patient population. Medical Care. 1988;26(7):724-735.

50. Özhayat E, Gotfredsen K. Effect of treatment with fixed and removable dental prostheses. an oral health-related quality of life study. Journal of Oral Rehabilitation. 2012;39(1):28-36.

51. Heydecke G. Implantologie: Wohlbefinden fur senioren. Zahnarztl Mitt. 2000;90:5257.

52. Gift H, Atchison K. Oral health, health, and health-related quality of life. Medical Care. 1995;33(11 Suppl):NS57-77.

53. Allen P, McMillan A. A longitudinal study of quality of life outcomes in older adults requesting implant prostheses and complete removable dentures. Clinical Oral Implants Research. 2003;14:173-179.

54. Heydecke G, Tedesco L, Kowalski C, et al. Complete dentures and oral health-related quality of life-do coping styles matter? Community Dentistry and Oral Epidemiology. 
2004;32(4):297-306.

55. Ikebe K, Watkins C, Ettinger R, et al. Application of short-form oral health impact profile on elderly. Gerodontology. 2004;21(3):167-176.

56. Allen F, Locker D. A modified short version of the oral health impact profile for assessing health-related quality of life in edentulous adults. The International Journal of Prosthodontics. 2002;15:446-450.

57. Oh S, Kim Y, Park J, Jung Y, Kim S, Park S. Comparison of fixed implant-supported prostheses, removable implant-supported prostheses, and complete dentures; patient satisfaction and oral health-related quality of life. Clinical Oral Implants Research. 2016;27(2):31-37.

58. Montero J, Bravo M, López-Valverde A. Development of a specific indicator of the well-being of wearers of removable dentures. Community Dentistry and Oral Epidemiology. 2011;39(6):515-524.

59. Montero J, Bravo M, Albaladejo A. Validation of two complementary oral healthrelated quality of life indicators (OIDP and OSS 0-10) in two qualitatively distinct samples of the spanish population. Health and Quality of Life Outcomes. 2008;18:6-101.

60. Streiner D, Norman G. Health measurement scales. A practical guide to their development and use. New York: Oxford University Press Inc. 1995;4.

61. Perea C, Del Río J, Preciado A, Lynch C, Celemín A, Castillo-Oyagüe R. Validation of the 'Quality of life with implant prostheses (QoLIP-10)' questionnaire for wearers of 
cement-retained implant-supported restorations. J Dent. 2015;43(8):1021-1031.

62. Jung R, Pjetursson B, Glauser R, Zembric A, Zwahlen M, Lang N. A systemic review of the 5-year survival and complication rates of implant-supported single crowns. Clinical Oral Implants Research. 2008;19(2):119-130.

63. Nickenig H, Wichmann M, Terheyden H, Kreppel M. Oral health-related quality of life and implant therapy: A prospective multicenter study of preoperative, intermediate, and posttreatment assessment. Journal of Cranio-maxillo-facial Surgery: official publication of the European Association for Cranio-Maxillo-Facial-Surgery. 2016;44(6):753-757.

64. Muddugangadhar B, Amarnath G, Sonika R, Chheda P, Garg A. Meta-analysis of failure and survival rate of implant-supported single crowns, fixed partial denture, and implant tooth-supported prostheses. Journal of International Oral Health: JIOH. 2015;7(9):11-17.

65. Nedir R, Bischof M, Szmukler-Moncler S, Belser U, Samson J. Prosthetic complications with dental implants: From an up-to-8-year experience in private practice. The International Journal of Oral \& Maxillofacial Implants. 2006;21(6):919-928.

66. Naert I, Quirynen M, van Steenberghe D, Darius P. A six-year prosthodontic study of 509 consecutively inserted implants for the treatment of partial edentulism. The Journal of Prosthetic Dentistry. 1992;67(2):236-245.

67. Priest G. Single-tooth implants and their role in preserving remaining teeth: A 10year survival study. The International Journal of Oral \& Maxillofacial Implants. 
1999;14(2):181-188.

68. Attard N, Zarb G. Long-term treatment outcomes in edentulous patients with implantfixed prostheses: The toronto study. The International Journal of Prosthodontics. 2004;17(4):417-424.

69. Ekfeldt A, Carlsson G, Börjesson G. Clinical evaluation of single-tooth restorations supported by osseointegrated implants: A retrospective study. The International Journal of Oral and Maxillofacial Implants. 1994;9:179-183.

70. Anderson B, Odman P, Lindvall A, Lithner B. Single-tooth restorations supported by osseointegrated implants: Results and experiences from a prospective study after 2-3 years. The International Journal of Oral and Maxillofacial Implants. 1995;10(6):702711.

71. Becker W, Becker B. Replacement of maxillary and mandibular molars with single endosseous implant restorations; a retrospective study

. The Journal of Prosthetic Dentistry. 1995;74(1):51-55.

72. Engquist B, Nilson H, Astrand P. Single-tooth replacement by osseointegrated brånemark implants. A retrospective study of 82 implants. Clinical Oral Implants Research. 1995;19(6):238-245.

73. Balshi T, Hernandez R, Pryszlak M, Rangert B. A comparative study of one implant versus two replacing a single molar. The International Journal of Oral and Maxillofacial 
Implants. 1996;11(3):372-378.

74. Henry P, Laney W, Jemt T, et al. Osseointegrated implants for single-tooth replacement: A prospective 5-year multicenter study. The International Journal of Oral and Maxillofacial Implants. 1996;11(4):450-455.

75. Walton J, MacEntee M. A prospective study on the maintenance of implant prostheses in private practice. The International Journal of Prosthodontics. 1997;10(5):453-458.

76. Behr M, Lang R, Leibrock A, Rosentritt M, Handel G. Complication rate with prosthodontic reconstructions on ITI and IMZ dental implants. Clinical Oral Implants Research. 1998;9(1):51-58.

77. Cooper L, Moriarty J. Prosthodontic and periodontal considerations for implantsupported dental restorations. Current Opinion in Periodontology. 1997;4:119-126.

78. Lai J, Albert F. Periodontics: Implant complications and maintenance issues. Oral Health Group. 2003.

79. Limmer B, Sanders A, Reside G, Cooper L. Complications and patient-centered outcomes with an implant-supported monolithic zirconia fixed dental prosthesis: 1 year results. Journal of Prosthodontics. 2014;23(4):267-275.

80. Douglass C, Shih A, Ostry L. Will there be a need for complete dentures in the united states in 2020? The Journal of Prosthetic Dentistry. 2002;87(1):5-8.

81. Cooper L. The current and future treatment of edentulism. The International Journal 
of Prosthodontics. 2009;18(2):116-122.

82. Fueki K, Kimoto K, Ogawa T, et al. Effect of implant-supported or retained dentures on masticatory performance: A systematic review. The Journal of Prosthetic Dentistry. 2007;98(6):470-477.

83. Yamada R, Gorin D, Marinello R, Rosen M, Russo S. Implant-supported overdentures: The standard of care for edentulous patients. The Periodontics Ltd. 2006.

84. Carlsson G, Lindquist L. Ten-year longitudinal study of masticatory function in edentulous patients treated with fixed complete dentures on osseointegrated implants. The International Journal of Prosthodontics. 1994;7(5):448-453.

85. Harris D, Höfer S, O'Boyle C, et al. A comparison of implant-retained mandibular overdentures and conventional dentures on quality of life in edentulous patients: A randomized, prospective, within-subject controlled clinical trial. Clinical Oral Implants Research. 2013;24(1):96-103.

86. Lindquist L, Rockler B, Carlsson G. Bone resorption around fixtures in edentulous patients treated with mandibular fixed tissue-integrated prostheses. The Journal of Prosthetic Dentistry. 1988;59(1):59-63.

87. Arvidson K, Bystedt H, Frykholm A, et al. Five year prospective follow up reported of the AstraTech dental implant system in the treatment of edentulous mandibles. Clinical Oral Implants Research. 1998;9:225-234.

88. von Wowern N, Gotfredsen K. Implant-supported overdentures, a prevention of bone 
loss in edentulous mandibles? A 5-year follow up study. Clinical Oral Implants Research. 2001;12(1):19-25.

89. Schwartz-Arad D, Kidron N, Dolev E. A long-term study of implants supporting overdentures as a model for implant success. Journal of Periodontology. 2005;76(9):1431-1435.

90. Attard N, Zarb G. Long-term treatment outcomes in edentulous patients with implant overdentures: The toronto study. The International Journal of Prosthodontics. 2004;17(4):425-433.

91. Bilhan H, Geckili O, Mumcu E, Bilmenoglu C. Maintenance requirements associated with mandibular implant overdentures: Clinical results after first year of service. Journal of Oral Implantology. 2011;37(6):697-704.

92. Hemmings K, Schmitt A, Zarb G. Complications and maintenace requirements for fixed prostheses and overdentures in the edentulous mandible: A 5-year report. The International Journal of Oral and Maxillofacial Implants. 1994;9(2):191-196.

93. Turkyilmaz I, Company A, McGlumphy E. Should edentulous patients be constrained to removable complete dentures? the use of dental implants to impvoe the quality of life for edentulous patients. Gerodontology. 2010;27(1):3-10.

94. Phillips K, Wong K. Vertical space requirement for the fixed-detachable, implantsupported prosthesis. Compendium of continuing education in dentistry. 2002;23:750752. 
95. Real-Osuna J, Almendros-Marqués N, Gay-Escoda C. Prevalence of complications after the oral rehabilitation with implant-supported hybrid prostheses. Medicina Oral, Patologia Oral y Cirugia Bucal. 2012;17(1):116-121.

96. Papaspyridakos P, Chen C, Chuang S, Weber H, Gallucci G. A systematic review of biologic and technical complications with fixed implant rehabilitations for edentulous patients. The International Journal of Oral \& Maxillofacial Implants. 2012;27(1):102110.

97. McAlarney M, Stavropoulous D. Theoretical cantilever lengths versus clinical variables in fifty-five clinical cases. The Journal of Prosthetic Dentistry. 2000;83(3):332343.

98. Wenger N, Mattson M, Furberg C, Elinson J. Assessment of quality of life in clinical trials of cardiovascular therapies. The American Journal of Cardiology. 1984;54(7):908913.

99. Ettinger R. Oral disease and its effect on the quality of life. Gerodontics. 1987;3:103106.

100. Agerberg G, Carlsson G. Chewing ability in relation to dental and general health. Acta Odontol Scand. 1981;39(3):147-153.

http://dx.doi.org/10.3109/00016358109162273. doi: 10.3109/00016358109162273.

101. Ekelund R. Dental state and subjective chewing ability of institutionalized elderly people. Community Dentistry and Oral Epidemiology. 1989;17(1):24-27. 
102. Giddon D. Oral health and the quality of life. The Journal of The American College of Dentists. 1987;54(2):10-15.

103. Stober T, Danner D, Lehmann F, Séché A, Rammelsberg P, Hassel A. Association between patient satisfaction with complete dentures and oral health-related quality of life: Two-year longitudinal assessment. Clinical Oral Investigations. 2010;16(1):313-318.

104. Sheiham A, Croog S. The psychosocial impact of dental diseases on individuals and communities. Journal of Behavioral Medicine. 1981;4(3):257-272.

105. al Quran F, Clifford T, Cooper C, Lamey P. Influence of psychological factors on the acceptance of complete dentures. Gerodontology. 2001;18(1):35-40.

106. Langer A, Michman J, Seifert I. Factors influencing satisfaction with complete dentures in geriatric patients. The Journal of Prosthetic Dentistry. 1961;11:1019-1031.

107. Yoshizumi D. An evaluation of the factors pertinent to success of complete denture service. The Journal of Prosthetic Dentistry. 1964;14:866-878.

108. Berg E, Johnsen B, Ingebretsen R. Psychological variables and patient acceptance of complete dentures. Acta Odontologica Scandinavica. 1986;44(1):17-22.

109. Boretti G, Bickel M, Geering A. A review of masticatory ability and efficiency. The Journal of Prosthetic Dentistry. 1995;74(4):400-403.

110. Preciado A, Del Río J, Suárez-García M, Montero J, Lynch C, Castillo-Oyagüe R. Differences in impact of patient and prosthetic characteristics on oral health-related quality of life among implant-retained overdenture wearers. Journal of Dentistry. 
2012;40(10):857-865

111. Perea C, Suárez-García M, Del Río J, Torres-Lagares D, Montero J, Castillo-Oyagüe R. Oral health-related quality of life in complete denture wearers depending on their socio-demographic background, prosthetic-related factors and clinical condition. Medicina Oral Patologia Oral y Cirugia Bucal. 2013;18(3):371-380.

112. Friedman N, Landesman H, Wexler M. The influences of fear, anxiety, and depression on patient's adaptive responses to complete dentures. part I. The Journal of Prosthetic Dentistry. 1987;58(6):687-689.

113. Friedman N, Landesman H, Wexler M. The influences of fear, anxiety, and depression on the patient's adaptive responses to complete dentures. part II. The Journal of Prosthetic Dentistry. 1988;59(1):45-48.

114. Awad M, Rashid F, Feine J. The effect of mandibular 2-implant overdentures on oral health-related quality of life: An international multicentre study. Clinical Oral Implants Research. 2014;25(1):46-51.

115. Hutton J, Heath M, Chai J, et al. Factors related to success and failure rates at 3-year follow-up in a multicenter study of overdentures supported by brånemark implants. The International Journal of Oral and Maxillofacial Implants. 1995;10(1):33-42.

116. Jemt T, Chai J, Harnett J, et al. A 5-year prospective multicenter follow-up report on overdentures supported by osseointegrated implants. The International Journal of Oral and Maxillofacial Implants. 1996;11(3):291-298. 
117. Bergendal T, Engquist B. Implant-supported overdentures: A longitudinal prospective study. The International Journal of Oral and Maxillofacial Implants. $1998 ; 13(2): 253-262$.

118. Feine J, Dufresne E, Boudrias P, et al. Outcome assessment of implant-supported prostheses. The Journal of Prosthetic Dentistry. 1998;79(5):575-579.

119. Martín-Ares M, Barona-Dorado C, Guisado-Moya B, Martínez-Rodríguez N, Cortés-Bretón-Brinkmann J, Martínez-González J. Prosthetic hygiene and functional efficacy in completely edentulous patients: Satisfaction and quality of life during a 5-year follow-up. Clinical Oral Implants Research. 2015.

120. Strassburger C, Kerschbaum T, Heydecke G. Influence of implant and conventional prostheses on satisfaction and quality of life: A literature review. part 2: Qualitative analysis and evaluation of the studies. The International Journal of Prosthodontics. 2006;19(4):339-348.

121. Yunus N, Masood M, Saub R, Al-Hashedi A, Taiyeb Ali T, Thomason J. Impact of mandibular implant prostheses on the oral health-related quality of life in partially and completely edentulous patients. Clinical Oral Implants Research. 2016;27(7):904-909.

122. Allen P, Locker D. Do item weights matter? an assessment using the oral health impact profile. Community Dental Health. 1997;14(3):133-138.

123. Goodacre C, Kan J, Rungcharassaeng K. Clinical complications of osseointegrated implants. The Journal of Prosthetic Dentistry. 1999;81(5):537-552. 
124. Goodacre C, Bernal G, Rungcharassaeng K. Clinical complications with implants and implant prostheses. The Journal of Prosthetic Dentistry. 2003;90(2):121-132.

125. Thomopoulou I, Thomopoulou D, Koutsouki D. The differences at quality of life and loneliness between elderly people. Biology of Exercise. 2010;6.2.

126. Silverman S, Silverman S, Silverman B, Garfinkel L. Self-image and its relation to denture acceptance. The Journal of Prosthetic Dentistry. 1976;35(2):131-141.

127. Leles C, Ferreira N, Vieira A, Campos A, Silva E. Factors influencing edentulous patients' preferences for prosthodontic treatment. Journal of Oral Rehabilitation. 2011;38(5):333-339.

128. Awad M, Shapiro S, Lund J, Feine J. Determinants of patients' treatment preferences in a clinical trial. Community Dentistry and Oral Epidemiology. 2000;28(2):119-125.

129. Awad M, Feine J. Measuring patient satisfaction with mandibular prostheses. Community Dentistry and Oral Epidemiology. 1998;26(6):400-405.

130. John M, Slade G, Szentpétery A, Setz J. Oral health-related quality of life in patients treated with fixed, removable, and complete dentures 1 month and 6 to 12 months after treatment. The International Journal of Prosthodontics. 2004;17(5):503-511. 


\section{Curriculum Vitae}

Jessica E. Canallatos, D.D.S.

2201 Hayden Lane, Morgantown, WV 26505 | (716) 572-2340| jesilvestri@mix.wvu.edu

\section{EDUCATION}

West Virginia University, Morgantown, WV

[M.S. in Prosthodontics]- expected graduation May 2017

2014-Present

State University of New York at Buffalo School of Dental Medicine, Buffalo, NY

Doctor of Dental Surgery

2010-2014

Magna Cum Laude

State University of New York at Geneseo, Geneseo, NY

B.S. in Biology

2006-2010

\section{MEMBERSHIPS}

American Cleft Palate-Craniofacial Association

American College of Prosthodontists

Academy of Osseointegration

Delta Sigma Delta

\section{LANGUAGES}

[English - native language] 